\title{
HACIA UN MAYOR ACCESO A LA JUSTICIA EN EL PROCESO PENAL COMENTARIO A LA SENTENCIA DEL TRIBUNAL CONSTITUCIONAL DE CHILE SOBRE LA INAPLICABILIDAD DE LOS ARTÍCULOS 230, 231, 237, 240 DEL CÓDIGO PROCESAL PENAL
}

\author{
Gonzalo Aguilar Cavallo ${ }^{1}$ \\ Profesor de Derecho Internacional Público y Derechos Humanos \\ gaguilarch@hotmail.com
}

El Tribunal Constitucional de Chile, con fecha 29 de enero de 2010, pronunció una sentencia en un recurso de inaplicabilidad presentado por Eduardo Sánchez Eyquem con el objeto de que se declarara la inaplicabilidad por inconstitucionalidad de los artículos 230, inciso primero, 231, 237, incisos primero, segundo, tercero letra a), cuarto, quinto, séptimo y octavo, y 240 , inciso segundo, del Código Procesal Penal, en una causa criminal por delito de lesiones graves. El Tribunal Constitucional rechazó la acción de inaplicabilidad con una prevención del Ministro Bertelsen y la Ministra Peña Torres y con la disidencia del Ministro Colombo Campbell. Este proceso se inserta en el contexto de otros reproches de constitucionalidad formulados contra las normas contenidas en el Código Procesal Penal, especialmente en los casos de César Uribe Villegas (18 diciembre 2008), Patricio Meneses Farías (19 agosto 2008) y Aarón Vásquez Muñoz (30 enero 2008).

El presente caso presentaba un desafío mayor, ya que se encontraba en juego el derecho de acceso a la justicia en el proceso penal, principio que forma parte de los fundamentos de la existencia de cualquier sociedad democrática. Por tanto, este comentario se centrará en el análisis del derecho de acceso a la justicia.

\footnotetext{
${ }^{1}$ Profesor de Derecho Internacional Público y Derechos Humanos, Doctor en Derecho, LLM en Derechos Humanos y Derecho Humanitario, MA en Relaciones Internacionales. Becario de investigación posdoctoral (DAAD / CONICYT) en el Max Planck Institute for Comparative Public Law and International Law, Ruprecht Karls Universität, Heidelberg, Alemania. El autor agradece el apoyo brindado por el DAAD, CONICYT y el Max Planck Institute for Comparative Public Law and International Law, en cuyo marco se ha realizado esta investigación (gaguilarch@hotmail.com).
} 


\section{HeCHOS}

1. La acción de inaplicabilidad tiene su origen en el proceso por el delito de lesiones graves, RIT No 6118-2009, RUC No 0900447112-9, del Cuarto Juzgado de Garantía de Santiago. El requirente señaló que "en calidad de ofendido personal por el delito de lesiones graves, previsto y sancionado en el artículo 397 del Código Penal, presentó una querella criminal [...]. Indica que la querella fue declarada admisible y enviada a la Fiscalía Oriente del Ministerio Público. Expone que los preceptos impugnados son decisivos para la gestión judicial pendiente, toda vez que otorgan al Ministerio Público amplias facultades para formalizar discrecionalmente y para solicitar, previo acuerdo del imputado, la suspensión condicional del procedimiento, lo que tiene el efecto final de extinguir la acción y la responsabilidad penal en el evento establecido en el inciso segundo del artículo 240 del Código Procesal Penal”'.

2. Además, precisó que "si bien el artículo 237, inciso quinto, del citado Código ordena oír al querellante que asistiere a la audiencia en que se ventile la suspensión condicional, sus derechos quedan completamente condicionados a las decisiones que adopte el Ministerio Público, toda vez que la formalización efectuada por tal organismo y la consiguiente calificación jurídica del o de los delitos por los cuales formaliza no es controlada judicialmente. Explica que, como consecuencia de la falta del aludido control, el querellante por el delito de lesiones graves quedará privado definitivamente del ejercicio de la acción penal pública, pues no podrá acceder a un pronunciamiento jurisdiccional si el ente persecutor, para los efectos de llegar a un acuerdo con el imputado y así proceder fácilmente a la suspensión condicional del procedimiento, formaliza por un delito que tenga asignada una pena inferior a la de presidio menor en su grado máximo"3.

3. Finalmente, el requirente señaló que "la aplicación de los preceptos impugnados, en cuanto consagran la formalización de la investigación y la suspensión condicional del procedimiento, vulnera lo dispuesto en los artículos $1^{\circ}, 5^{\circ}$, inciso

\footnotetext{
${ }^{2}$ Tribunal Constitucional de Chile: Requerimiento de inaplicabilidad por inconstitucionalidad de Eduardo Sánchez Eyquem respecto de los artículos 230, inciso primero, 231, 237, incisos primero, segundo, tercero letra a), cuarto, quinto, séptimo y octavo, y 240, inciso segundo, del Código Procesal Penal, en el proceso por el delito de lesiones graves, RIT No 6118-2009, RUC No 0900447112-9, del Cuarto Juzgado de Garantía de Santiago. Rol No 1445-09. Sentencia de fecha 29 de enero de 2010, p. 1.

${ }^{3}$ Tribunal Constitucional de Chile: Requerimiento de inaplicabilidad por inconstitucionalidad de Eduardo Sánchez Eyquem respecto de los artículos 230, inciso primero, 231, 237, incisos primero, segundo, tercero letra a), cuarto, quinto, séptimo y octavo, y 240, inciso segundo, del Código Procesal Penal, en el proceso por el delito de lesiones graves, RIT No 6118-2009, RUC No 0900447112-9, del Cuarto Juzgado de Garantía de Santiago. Rol No 1445-09. Sentencia de fecha 29 de enero de 2010, p. 2.
} 
segundo, $19, \mathrm{No}^{\circ}$. $3^{\circ}$, incisos primero, segundo, tercero, quinto y sexto, y $26^{\circ}$, 76 y 83 de la Constitución Política. Agrega que, además, debe acogerse la acción impetrada en estos autos por cuanto también se configuraría una contravención a los numerales 1 y 2 del artículo $8^{\circ}$ de la Convención Americana sobre Derechos Humanos en relación con el artículo $5^{\circ}$ de la Carta Fundamental".

4. En la sentencia que comentamos existe un relevante voto disidente, el cual a su vez, reproduce, en parte, los argumentos de un voto de mayoría, en un caso anterior, del mismo tribunal ${ }^{4}$. Pocas veces los votos disidentes forman parte del comentario jurídico. Nosotros consideramos que el voto disidente del Ministro Campbell constituye un aporte al debate constitucional en materia de acceso a la justicia. Por lo tanto, a continuación, nos referiremos primero al voto de mayoría y, posteriormente, abordaremos el voto disidente del Ministro Campbell, ya que efectúa un notable examen del derecho de acceso a la justicia, aun cuando, en nuestra opinión, su voto sería aun más potente si portara una visión global y coherente de los derechos humanos fundamentales, integrando así el enfoque del Derecho Internacional de los Derechos Humanos, tal como fue planteado por el requirente en su acción de inaplicabilidad. Esta integración en la ecuación constitucional del Derecho Internacional de los Derechos Humanos es una tendencia actual en la evaluación que efectúan gran parte de los tribunales constitucionales de América Latina y del mundo.

\section{VoTO DE MAYORÍA}

1. Los jueces constitucionales se concentraron en el argumento de la naturaleza del reproche de constitucionalidad efectuado por el requirente. Así, señalaron que "en el caso concreto en que se ha solicitado pronunciamiento de inaplicabilidad, los preceptos impugnados no tienen una posibilidad real de ser aplicados y ser decisivos, sino tan sólo una posibilidad hipotética y teórica, y es menester diferenciar estas situaciones, por cuanto la segunda de ellas no amerita un pronunciamiento de este sentenciador, desde el momento en que no ha sido llamado a emitir pronunciamientos de inaplicabilidad de eficacia hipotética. En razón de lo anterior es que se ha "afirmado que el requerimiento de inaplicabilidad procede contra un precepto legal, de cualquier naturaleza, que se estima contrario a la Carta Fundamental; la exigencia constitucional se completa si dicho precep-

\footnotetext{
${ }^{4}$ En este sentido, vid. Tribunal Constitucional de Chile: Requerimiento de inaplicabilidad presentado por Patricio Rodrigo Meneses Farías respecto del artículo 230, inciso primero, del Código Procesal Penal, en la causa RIT No 179-2005, RUC No 0510001570-08, del Juzgado de Garantía de San Fernando. Rol No 815-07. Sentencia de 19 de agosto de 2008.
} 
to legal puede resultar decisivo en la resolución del asunto o gestión pendiente, lo que implica que la inaplicabilidad declarada deba ser considerada por el juez llamado a resolverla, tanto en lo que se refiere a los fundamentos de ésta cuanto a todo otro razonamiento que implique que la decisión del asunto no resultará contraria a la Constitución" 5 .

2. Además, los jueces constitucionales agregaron que "debe precisarse que el requerimiento de autos tampoco podría ser objeto de una sentencia estimatoria, desde el momento en que, al apoyarse en elucubraciones sobre el curso futuro del proceso penal pendiente prescindiendo de circunstancias concretas y reales, envuelve más bien una pretensión de inconstitucionalidad en abstracto respecto de institutos procesales como lo son la formalización de la investigación y las salidas alternativas, cuestión que, sin perjuicio de ser desestimada por las motivaciones contenidas en el capítulo III de esta sentencia, no puede ser objeto de una declaración de inaplicabilidad"6.

3. El Tribunal Constitucional finalmente rechazó la acción de inaplicabilidad observando que "es posible colegir que la acción de inaplicabilidad formulada no podrá ser acogida, atendido que se ha efectuado un reproche de inconstitucionalidad en abstracto respecto de disposiciones que no tienen la aptitud de ser decisorias y de producir efectos contrarios a la Constitución Política en el estado actual del proceso penal pendiente" 7 .

4. Como se puede observar, el Tribunal Constitucional no efectuó un análisis detallado del requerimiento a la luz del derecho de acceso a la justicia. En cambio, el voto disidente se enfocó justamente en el examen de este principio.

\footnotetext{
${ }^{5}$ Tribunal Constitucional de Chile: Requerimiento de inaplicabilidad por inconstitucionalidad de Eduardo Sánchez Eyquem respecto de los artículos 230, inciso primero, 231, 237, incisos primero, segundo, tercero letra a), cuarto, quinto, séptimo y octavo, y 240, inciso segundo, del Código Procesal Penal, en el proceso por el delito de lesiones graves, RIT No 6118-2009, RUC No 0900447112-9, del Cuarto Juzgado de Garantía de Santiago. Rol No 1.445-09. Sentencia de fecha 29 de enero de 2010, considerando 36.

${ }^{6}$ Tribunal Constitucional de Chile: Requerimiento de inaplicabilidad por inconstitucionalidad de Eduardo Sánchez Eyquem respecto de los artículos 230, inciso primero, 231, 237, incisos primero, segundo, tercero letra a), cuarto, quinto, séptimo y octavo, y 240, inciso segundo, del Código Procesal Penal, en el proceso por el delito de lesiones graves, RIT No 6118-2009, RUC No 0900447112-9, del Cuarto Juzgado de Garantía de Santiago. Rol No 1.445-09. Sentencia de fecha 29 de enero de 2010, considerando 37\%.

7 Tribunal Constitucional de Chile: Requerimiento de inaplicabilidad por inconstitucionalidad de Eduardo Sánchez Eyquem respecto de los artículos 230, inciso primero, 231, 237, incisos primero, segundo, tercero letra a), cuarto, quinto, séptimo y octavo, y 240, inciso segundo, del Código Procesal Penal, en el proceso por el delito de lesiones graves, RIT No 6118-2009, RUC No 0900447112-9, del Cuarto Juzgado de Garantía de Santiago. Rol No 1.445-09. Sentencia de fecha 29 de enero de 2010, considerando 42。.
} 


\section{VOTO DISIDENTE}

1. El voto disidente del Ministro Colombo Campbell, en el caso Eduardo Sánchez Eyquem, resalta los derechos fundamentales como los valores jurídicos fundamentales del ordenamiento constitucional. En efecto, el voto disidente señala que "cabe concluir que el delito se concibe, desde una perspectiva constitucional, como una forma de sancionar y restablecer el imperio del derecho frente a la violación de valores jurídicos fundamentales de la convivencia social, que no son otros que los mismos protegidos por las garantías que la Constitución asegura a todas las personas".

2. El voto disidente efectúa un esbozo general del contenido del derecho a la tutela judicial efectiva. En efecto, el Ministro Campbell nos recuerda que "debe reiterarse que este conjunto de derechos fundamentales incluye el acceso a la jurisdicción como presupuesto para lograr el derecho a la "tutela judicial efectiva" de sus derechos constitucionales, conceptualizada ésta por los especialistas como "aquel (derecho) que tiene toda persona a obtener tutela efectiva de sus derechos e intereses legitimos ante el juez ordinario predeterminado por la ley y a través de un proceso con todas las garantías, sin dilaciones indebidas y en el que no se produzca indefensión"9. Este derecho, como ya se viera, incluye el libre acceso a la jurisdicción, entendido como la posibilidad de formular pretensiones ante el juez y obtener una resolución acerca de las mismas -independientemente del ente persecutor estatal-, así como el derecho a la ejecución de las resoluciones judiciales, la interdicción de la indefensión y el derecho al debido proceso, con la plena eficacia de todas las garantías que le son propias"10.

3. Además, el voto disidente afirma la existencia, en derecho comparado, del derecho a la tutela judicial efectiva, cuyo conjunto valórico normativo se

\footnotetext{
${ }^{8}$ Tribunal Constitucional de Chile: Requerimiento de inaplicabilidad por inconstitucionalidad de Eduardo Sánchez Eyquem respecto de los artículos 230, inciso primero, 231, 237, incisos primero, segundo, tercero letra a), cuarto, quinto, séptimo y octavo, y 240, inciso segundo, del Código Procesal Penal, en el proceso por el delito de lesiones graves, RIT No 6118-2009, RUC No 0900447112-9, del Cuarto Juzgado de Garantía de Santiago. Rol No 1445-09. Sentencia de fecha 29 de enero de 2010. Voto disidente del Ministro señor Juan Colombo Campbell. Considerando $5^{\circ}$.

${ }^{9}$ Balaguer Callejón, Francisco (Coord.): Manual de Derecho Constitucional. Tomo II, Ed. Tecnos, Madrid, 2005, p. 221.

${ }^{10}$ Tribunal Constitucional de Chile: Requerimiento de inaplicabilidad por inconstitucionalidad de Eduardo Sánchez Eyquem respecto de los artículos 230, inciso primero, 231, 237, incisos primero, segundo, tercero letra a), cuarto, quinto, séptimo y octavo, y 240, inciso segundo, del Código Procesal Penal, en el proceso por el delito de lesiones graves, RIT No 6118-2009, RUC No 0900447112-9, del Cuarto Juzgado de Garantía de Santiago. Rol No 1445-09. Sentencia de fecha 29 de enero de 2010. Voto disidente del Ministro señor Juan Colombo Campbell. Considerando $10^{\circ}$.
} 
encuentra incorporado en la Constitución chilena. En este sentido, el Ministro Colombo Campbell señala que "las constituciones europeas, inmersas en las corrientes predominantes del constitucionalismo de nuestros tiempos, consagran el derecho fundamental de toda persona a la tutela judicial efectiva de sus intereses y derechos, destacándose, en esta específica línea de garantismo, lo dispuesto por la Carta española, en su artículo 24.2. [...] Es en esta línea de pensamiento que la Constitución chilena, más allá de las normas citadas de su texto y de las interpretaciones que de ellas se han hecho, reconoce de manera expresa el conjunto valórico normativo que configura la tutela judicial efectiva, declarando también que los derechos fundamentales deben ser respetados y promovidos por todos los órganos del Estado, lo que incluye, natural y especialmente en el caso de los procesos penales, al Ministerio Público, por mandato constitucional expreso y además por la naturaleza propia de las funciones que tiene, según se desprende de los artículos $1^{\circ}, 5^{\circ}, 6^{\circ}, 19$, números $2^{\circ}, 3^{\circ}$ y $26^{\circ}$, y 83 de la Carta Fundamental, debiendo potenciarlos con sus actos realizados en el marco de su competencia"11.

4. Respecto del derecho a la tutela judicial efectiva, el voto disidente afirma que se trata de una norma "autosuficiente y autoejecutiva", lo que, aunque, a nuestro entender, pudiera parecer obvio, no siempre es aceptado. Además, agrega que "los operadores del sistema procesal penal, entre los que destacan el juez y el Ministerio Público, deben garantizar al ofendido el pleno ejercicio de sus derechos en el proceso penal y todo acto o hecho que lo limite debe considerarse que atenta en contra de sus garantías constitucionales"12.

5. De esta manera, el Ministro Colombo Campbell concluye que "la aplicación de los preceptos impugnados, en orden a formalización parcial, impide el libre acceso a la jurisdicción, que la imposición de salidas alternativas en contra de la voluntad del afectado lo priva de sus intereses tutelables y del ejercicio de la acción y que la negativa a realizar diligencias de investigación tendientes a

\footnotetext{
${ }^{11}$ Tribunal Constitucional de Chile: Requerimiento de inaplicabilidad por inconstitucionalidad de Eduardo Sánchez Eyquem respecto de los artículos 230, inciso primero, 231, 237, incisos primero, segundo, tercero letra a), cuarto, quinto, séptimo y octavo, y 240, inciso segundo, del Código Procesal Penal, en el proceso por el delito de lesiones graves, RIT No 6118-2009, RUC No 0900447112-9, del Cuarto Juzgado de Garantía de Santiago. Rol No 1445-09. Sentencia de fecha 29 de enero de 2010. Voto disidente del Ministro señor Juan Colombo Campbell. Considerando $11^{\circ}$.

${ }^{12}$ Tribunal Constitucional de Chile: Requerimiento de inaplicabilidad por inconstitucionalidad de Eduardo Sánchez Eyquem respecto de los artículos 230, inciso primero, 231, 237, incisos primero, segundo, tercero letra a), cuarto, quinto, séptimo y octavo, y 240, inciso segundo, del Código Procesal Penal, en el proceso por el delito de lesiones graves, RIT No 6118-2009, RUC No 0900447112-9, del Cuarto Juzgado de Garantía de Santiago. Rol No 1445-09. Sentencia de fecha 29 de enero de 2010. Voto disidente del Ministro señor Juan Colombo Campbell. Considerando $20^{\circ}$.
} 
aclarar los hechos objeto de la querella constituye una privación del derecho a la investigación, todos de rango constitucional, por lo que la aplicación de los preceptos impugnados al caso sub lite infringe la Carta Fundamental, en específico el numeral $3^{\circ}$ de su artículo 19 y su artículo 83 , además de sus artículos $1^{\circ}, 5^{\circ}$, $6^{\circ}, 7^{\circ}$ y 19 , número $26^{\circ}{ }^{13}$.

\section{IV. ¿QUÉ LE FALTARÍA A LA MAYORÍA Y AL VOTO DISIDENTE?}

1. La consideración de los principios y estándares de acceso a la justicia, reconocidos y consagrados en el Derecho Internacional de los Derechos Humanos, pese a que el requirente los invocó en su presentación. ¿Por qué es importante incorporar este enfoque? Porque las garantías constitucionales de los derechos humanos son informadas, orientadas, complementadas, completadas y ampliadas, por las normas internacionales de derechos humanos respecto de las cuales el Estado mismo ha otorgado su consentimiento en obligarse. Existe incluso un mandato constitucional en este sentido -que vincula también al Tribunal Constitucional-, contenido en el artículo $5^{\circ}$ de la Constitución Política de Chile. Podría sostenerse que el juez constitucional no está obligado a considerar los contenidos y extensiones internacionales de los derechos fundamentales y debería sólo sujetarse a la letra de la Constitución. Sin embargo, el rol primordial del juez constitucional va mucho más allá que simplemente ser el guardián de la letra de la Constitución y comprende una función protectora de los valores y principios constitucionales ${ }^{14}$. Dentro de estos valores constitucionales fundamentales se encuentran la dignidad humana y su especificación normativa a través de los derechos humanos fundamentales ${ }^{15}$. En

\footnotetext{
${ }_{13}$ Tribunal Constitucional de Chile: Requerimiento de inaplicabilidad por inconstitucionalidad de Eduardo Sánchez Eyquem respecto de los artículos 230, inciso primero, 231, 237, incisos primero, segundo, tercero letra a), cuarto, quinto, séptimo y octavo, y 240, inciso segundo, del Código Procesal Penal, en el proceso por el delito de lesiones graves, RIT No 6118-2009, RUC No 0900447112-9, del Cuarto Juzgado de Garantía de Santiago. Rol No 1445-09. Sentencia de fecha 29 de enero de 2010. Considerando $21^{\circ}$.

14 " $[E] l$ derecho a la identidad personal está estrechamente ligado a la dignidad humana, en cuanto valor que, a partir de su consagración en el artículo $1^{\circ}$, inciso primero, de la Ley Suprema, constituye la piedra angular de todos los derechos fundamentales que la Ley Suprema consagra". Tribunal Constitucional de Chile: Requerimiento de inaplicabilidad por inconstitucionalidad del Juez Presidente del Juzgado de Familia de Pudahuel, señor Carlo Marcelo Casaula Mezzano respecto del artículo 206 del Código Civil, en la causa RIT $N^{o}$ C-111-2009, seguida por investigación/reclamación de paternidad, caratulada "Muñoz con Muñoz". Rol No 1340-2009. Sentencia de fecha 29 de septiembre de 2009. Considerando $9^{\circ}$.

${ }^{15}$ El Ministro Colombo Campbell los denomina "valores jurídicos fundamentales de la convivencia social". Tribunal Constitucional de Chile: Requerimiento de inaplicabilidad por inconstitucionalidad de Eduardo Sánchez Eyquem respecto de los artículos 230, inciso primero, 231, 237, incisos primero, segundo, tercero letra a), cuarto, quinto, séptimo y octavo, y 240, inciso segundo, del Código Procesal Penal, en el proceso por el delito de lesiones graves, RIT No 6118-2009, RUC No 0900447112-9, del Cuarto Juzgado de Garantía de Santiago.
} 
esta tarea se requiere una interpretación finalista y evolutiva que permita construir los valores constitucionales integralmente y no sólo parcialmente. La integralidad de los valores constitucionales de los derechos fundamentales implica incorporar la dimensión internacional a su entendimiento. Sólo así, a nuestro modo de ver, se satisface, por los jueces constitucionales, el mandato constitucional primario y prioritario de protección de la dignidad humana. En esta línea, el juez constitucional contemporáneo, además de ser guardián de la Constitución, es el guardián de los valores y principios constitucionales. Y, en este contexto, el valor de la dignidad humana ocupa la cúspide del sistema de principios constitucionales. Al juez constitucional corresponde dar pues, a estos valores y principios, operatividad real para el ser humano.

2. En el presente caso y en los que se abordará en el apartado V, el voto de mayoría no contiene una referencia al Derecho Internacional de los Derechos Humanos. Esta actitud de desconsideración de los contenidos de los derechos individuales provenientes del orden internacional plantea un problema en el orden doméstico del Estado. La opción de complementar el orden jurídico interno con el Derecho Internacional de los Derechos Humanos verosímilmente otorgaría una mayor protección al individuo y ello podría arrojar resultados jurídicos diversos a los obtenidos finalmente a través de los votos de mayoría. Quizás vale la pena recordar que, en el ámbito del sistema procesal penal, los resultados jurídicos diversos irían a favor de todos los actores involucrados en el proceso, particularmente, imputado y víctima.

3. Resulta incluso más cuestionable esta falta de consideración de los elementos provenientes del Derecho Internacional de los Derechos Humanos si se tiene en cuenta que el Tribunal Constitucional ha recurrido a ellos en otras notables ocasiones. Baste citar para demostrar aquello la sentencia pronunciada en el denominado caso de la píldora del día después, en donde el fallo del Tribunal efectuó una armonización de los contenidos de la Constitución con aquellos del Derecho Internacional de los Derechos Humanos, particularmente, con la Convención Americana sobre Derechos Humanos y la jurisprudencia derivada de ella ${ }^{16}$. A mayor abundamiento, en un reciente caso sobre el derecho a la identidad,

Rol No 1445-09. Sentencia de fecha 29 de enero de 2010. Voto disidente del Ministro señor Juan Colombo Campbell. Considerando $5^{\circ}$.

16 Tribunal Constitucional Chileno: Requerimiento de inconstitucionalidad deducido en contra de algunas disposiciones de las "Normas Nacionales sobre Regulación de la Fertilidad", aprobadas por el Decreto Supremo No 48, de 2007, del Ministerio de Salud. Rol No 740-2008. Sentencia de fecha 18 de abril de 2008; Vid. Aguilar Cavallo, Gonzalo: "Hacia un sistema integral de Derechos Humanos: Comentario a la sentencia del 
el Tribunal Constitucional recurrió a los contenidos del Derecho Internacional de los Derechos Humanos, especialmente, a la Convención Americana sobre Derechos Humanos para completar el contenido jurídico de los derechos del individuo que la Constitución chilena garantiza a todas las personas. Así, en este último caso, el Tribunal Constitucional ha señalado "que debe reconocerse, en efecto, que los diversos instrumentos internacionales, ratificados por Chile y vigentes, que cita el juez requirente en apoyo de su argumentación, consagran el derecho a la identidad personal generando, por ende, la obligación de los órganos del Estado de respetarlos y promoverlos, en los términos aludidos en el inciso segundo del artículo $5^{\circ}$ de la Carta Fundamental" ${ }^{17}$. Además, en este caso, los jueces constitucionales reiteran el paradigma de un sistema integral de derechos humanos, comprensivo y coherente, que ya había sido afirmado con anterioridad en la causa Rol No 843-2007 (13 de mayo de 2008). En efecto, en esta última causa, el Tribunal Constitucional chileno afirmó que "[s]obre el particular, ha de tenerse presente que aun cuando la Constitución chilena no lo reconozca expresamente en su texto, ello no puede constituir un obstáculo para que el juez constitucional le brinde adecuada protección. Lo anterior, precisamente, por su estrecha vinculación con la dignidad humana y porque tampoco puede desconocerse que él sí se encuentra protegido expresamente en diversos tratados internacionales ratificados por Chile y vigentes en nuestro país, como la Convención sobre los Derechos del Niño (artículo 7o), el Pacto Internacional de Derechos Civiles y Políticos (artículo 24.2) y la Convención Americana sobre Derechos Humanos (artículo 18)"18.

4. Una excelente formulación de la perspectiva de un sistema integral de los derechos humanos se encuentra en el caso sobre el derecho a la identidad. Allí, los jueces constitucionales afirmaron que "[l]as consideraciones que preceden justifican, precisamente, incluir el derecho a la identidad personal entre aquellos derechos esenciales a la naturaleza humana a que alude el artículo $5^{\circ}$, inciso se-

Tribunal Constitucional chileno sobre la píldora del día después", en Revista Ius et Praxis, Vol. 14, núm. 1 (2008), pp. 347-362.

${ }^{17}$ Tribunal Constitucional de Chile: Requerimiento de inaplicabilidad por inconstitucionalidad del Juez Presidente del Juzgado de Familia de Pudahuel, señor Carlo Marcelo Casaula Mezzano respecto del artículo 206 del Código Civil, en la causa RIT No C-111-2009, seguida por investigación/reclamación de paternidad, caratulada "Muñoz con Muñoz". Rol No 1340-2009. Sentencia de fecha 29 de septiembre de 2009. Considerando 9.

18 Tribunal Constitucional de Chile: Requerimiento de inaplicabilidad presentado por Julio Magri Rabaglio, respecto de los artículos 188, 199 y 199 bis del Código Civil, en relación a la causa caratulada "Magri con Magri", RIT No C-680-2007, RUC 07-2-0098411-5, del Cuarto Juzgado de Familia de Santiago. Rol No 834-2007. Sentencia de fecha 13 de mayo de 2008. Considerando $22^{\circ}$. 
gundo, de la Constitución, y que se erigen como límite de la soberanía, debiendo los órganos del Estado respetarlos y promoverlos, ya sea que estén asegurados en la propia Carta Fundamental o en tratados internacionales ratificados por Chile y que se encuentren vigentes" ${ }^{\prime 1}$. Teniendo presente las consideraciones precedentes nos surge la pregunta: ¿Por qué en estos casos -citados sólo a título de ejemplo-el Tribunal Constitucional ha desplegado una función constitucional de protección integral de los derechos de los individuos, recurriendo al Derecho Internacional de los Derechos Humanos, y en otros casos, como los que este texto comenta, no? ¿Es una actitud coherente? ¿Genera confianza en los individuos en cuanto a la previsibilidad del actuar del Tribunal Constitucional respecto a la protección integral de sus derechos?

5. Por otra parte, en ocasiones, en los votos disidentes se invoca el Derecho Internacional de los Derechos Humanos, y con ello se demuestra que el resultado jurídico, si se razona incorporando este ámbito de principios y normas, sería diverso al obtenido por la mayoría. En efecto, ello queda claro cuando se lee el excelente voto disidente del juez Vodanovic y Fernández, en el caso de Aarón Vásquez, el cual señala como parámetro de constitucionalidad una serie de instrumentos internacionales de derechos humanos pero, además, incorpora en su argumentación la jurisprudencia de la Corte Interamericana de Derechos Humanos (en adelante, la Corte IDH). Así es, los disidentes manifiestan que el ordenamiento en su conjunto "consagra la garantía de un procedimiento racional y justo y, en su contexto, del derecho a un recurso, en tanto que el sistema procesal penal vigente está orientado por la cautela de los derechos del imputado criminal y, en lo que concierne precisamente a la habilitación del recurso de nulidad, por la protección de los derechos o garantía asegurados por la Constitución o por los tratados internacionales ratificados por Chile que se encuentren vigentes". Los disidentes señalaron que el derecho al recurso del imputado criminal es expresamente reconocido en tratados internacionales ratificados por Chile, tales como el Pacto Internacional de Derechos Civiles y Políticos, la Convención Interamericana de Derechos Humanos, la Convención de Derechos del Niño. Los disidentes agregaron que "dichas reglas, que el Estado debe promover y respetar, son normas jurídicas y obligatorias. Desde el punto de vista constitucional se constituyen en parámetro de constitucionalidad o, al menos, en contenido sustancial de un

\footnotetext{
${ }^{19}$ Tribunal Constitucional de Chile: Requerimiento de inaplicabilidad por inconstitucionalidad del Juez Presidente del Juzgado de Familia de Pudahuel, señor Carlo Marcelo Casaula Mezzano respecto del artículo 206 del Código Civil, en la causa RIT No C-111-2009, seguida por investigación/reclamación de paternidad, caratulada "Muñoz con Muñoz". Rol No 1340-2009. Sentencia de fecha 29 de septiembre de 2009. Considerando 10º
} 
debido proceso" ${ }^{20}$. Además, los disidentes invocan la jurisprudencia de la Corte IDH citando el caso Herrera Ulloa vs. Costa Rica ${ }^{21}$.

6. Finalmente, en el contexto del acceso a la justicia, cabe agregar la perspectiva de la Corte Suprema de Chile. La óptica desde la cual dicha Corte ha abordado el derecho de acceso a la justicia plantea aun más interrogantes respecto de la retención en el razonamiento del Tribunal Constitucional. En efecto, para llenar de contenido el derecho de acceso a la justicia, la Corte Suprema ha recurrido a los tratados internacionales de derechos humanos tales como la Convención Americana sobre Derechos Humanos y el Pacto Internacional de Derechos Civiles y Políticos, ambos vinculantes para los órganos del Estado de Chile ${ }^{22}$. Además, la Corte Suprema ha utilizado como guía y a título informador, otros tratados internacionales que no son vinculantes para el Estado de Chile, pero que sirven para realizar una interpretación y llevar a cabo un razonamiento jurídico integral y coherente respecto de un derecho humano ${ }^{23}$. Es así como la Corte Suprema ha podido concluir que "a la luz de nuestra normativa constitucional (artículo 19 No 3, inciso $5^{\circ}$, de la Constitución Política), de las disposiciones de los tratados y convenciones internacionales que se han citado, y de los principios de derecho internacional que tales instrumentos recogen, resulta indudable que el objetivo de todo juicio penal, más allá de su fin puramente criminoso, está orientado fundamentalmente por la necesidad de garantizar al individuo, en el

\footnotetext{
${ }^{20}$ Tribunal Constitucional de Chile: Requerimiento de inaplicabilidad presentado por Aarón David Vásquez Muñoz, respecto del artículo 387, inciso segundo, del Código Procesal Penal, en causa RUC No 0600764824-1, del $8^{\circ}$ Juzgado de Garantía de Santiago. Rol No 986-2007. Sentencia de fecha 30 de enero de 2008. Considerando $27^{\circ}$. Voto disidente de los Ministros Hernán Vodanovic Schnake y Mario Fernández Baeza. Considerando $23^{\circ}$.

${ }^{21}$ Tribunal Constitucional de Chile: Requerimiento de inaplicabilidad presentado por Aarón David Vásquez Muñoz, respecto del artículo 387, inciso segundo, del Código Procesal Penal, en causa RUC No 0600764824-1, del $8^{\circ}$ Juzgado de Garantía de Santiago. Rol No 986-2007. Sentencia de fecha 30 de enero de 2008. Considerando $27^{\circ}$. Voto disidente de los Ministros Hernán Vodanovic Schnake y Mario Fernández Baeza. Considerando $26^{\circ}$.

${ }^{22}$ Corte Suprema de Chile: Iturriaga Neumann, Eduardo. Extradición pasiva. Rol No 3-2000. Sentencia de fecha 3 de octubre de 2000. Considerandos $16^{\circ}$ y $17^{\circ}$.

23 "Que, además de los convenios o tratados internacionales estudiados y citados precedentemente, resulta de manifiesta utilidad, en este caso, mencionar otros no de carácter precisamente regional, ni necesariamente vinculantes para nuestro país, pero que también recogen los principios de derecho internacional aplicables a esta materia, entre los que cabe mencionar la Convención de Salvaguardia de los Derechos del Hombre y de las Libertades Fundamentales o "Pacto de Roma", y el Convenio Europeo de Extradición de 1957 y sus Protocolos Adicionales, que adquieren en este caso relevancia, en razón de que el Estado requirente, la República de Italia, es parte contratante en esas Convenciones". Corte Suprema de Chile: Iturriaga Neumann, Eduardo. Extradición pasiva. Rol No 3-2000. Sentencia de fecha 3 de octubre de 2000. Considerando $18^{\circ}$.
} 
contexto de sus derechos constitucionales, un debido proceso y una investigación y juzgamiento racionales y justos, como una garantía superior para realizar la justicia, respetando los derechos humanos de las personas" ${ }^{24}$. Creemos que la Corte Suprema nos proporciona un ejemplo notable de un paso adelante en la dirección correcta.

\section{Algunos Casos de acceso a la justicia en materia Penal ante el Tribunal Constitucional}

1. Este reproche de constitucionalidad respecto del Código Procesal Penal se inserta en el contexto de otros reproches del mismo carácter que el Tribunal Constitucional previamente ha debido examinar y, consecuentemente, pronunciarse. En este comentario, haremos breves referencias a algunos de los otros reproches de constitucionalidad, con el fin de efectuar un análisis de contexto, atendido que, en general, también dicen relación con el derecho de acceso a la justicia. En el caso de marras, la violación del acceso a la justicia se produce respecto del ofendido, pero la legislación procesal penal también se encuentra en contradicción con el derecho de acceso a la justicia respecto de los derechos del imputado garantizados por la Constitución.

a) En el caso de Eduardo Sánchez Eyquem (29 enero 2010), en su calidad de ofendido personal por el delito, alega que los artículos impugnados (el artículo 230 inciso primero y 237 -entre otros- del Código Procesal Penal) otorgan al Ministerio Público la facultad discrecional de formalizar y para solicitar la suspensión condicional del procedimiento, lo que acarrea como consecuencia extinguir la acción y la responsabilidad penal. De esta manera queda entregado el derecho de acción y de acceso a la justicia del ofendido por el delito a las decisiones que adopte el Ministerio Público.

b) En el caso de César Uribe Villegas (18 diciembre 2008), el requirente es el juez Patricio Rondini Fernández-Dávila, quien alega la inaplicabilidad del artículo 149 del Código Procesal Penal, ya que impide dejar en libertad al imputado aun cuando el juez lo haya ordenado así, para el caso en que el Fiscal haya deducido recurso de apelación.

c) En el caso de Patricio Meneses Farías (19 agosto 2008), en su calidad de ofendido y querellante alega que el artículo impugnado (230 inciso primero del Código Procesal Penal) otorga una facultad discrecional al Ministerio Público, quien puede formalizar, sin respeto del interés jurídico del ofendido.

\footnotetext{
${ }^{24}$ Corte Suprema de Chile: Iturriaga Neumann, Eduardo. Extradición pasiva. Rol No 3-2000. Sentencia de fecha 3 de octubre de 2000. Considerando $21^{\circ}$.
} 
d) En el caso de Aarón Vásquez Muñoz (30 enero 2008), en su calidad de imputado, alega que el artículo impugnado afecta su derecho al recurso, a que el proceso sea revisado por un tribunal superior y, en consecuencia, al acceso a la justicia, ya que niega la procedencia del recurso en el caso que el artículo 387 inciso $2^{\circ}$ del Código Procesal Penal prevé.

Todos estos casos tienen que ver, de una u otra manera, con la vigencia plena del principio de acceso a la justicia en el proceso penal. En todo estos casos la acción de inaplicabilidad fue rechazada, salvo en el caso de Meneses Farías donde se acogió muy parcialmente.

\section{Precisiones del Tribunal Constitucional SOBRE EL PRINCIPIO DE ACCESO A LA JUSTICIA}

1. En primer lugar, desde un punto de vista conceptual, el Tribunal Constitucional utiliza generalmente diversas nociones pero en menor medida la de acceso a la justicia. En términos generales, el Tribunal Constitucional adopta la noción de tutela judicial efectiva e incorpora dentro de este concepto el derecho de acceso a la jurisdicción. En efecto, en el caso de Meneses Farías, el Tribunal Constitucional señala que "la Constitución, más allá de las normas citadas de su texto, reconoce de manera expresa el conjunto valórico normativo que configura la tutela judicial efectiva de los derechos e intereses de las personas, declarando también que los derechos fundamentales deben ser respetados y promovidos por todos los órganos del Estado, incluido especialmente el Ministerio Público, según se desprende de los artículos $1^{\circ}, 5^{\circ}, 6^{\circ}$ y 19 , números $2^{\circ}, 3^{\circ}$ y 26 , de la Carta Fundamental" 25 . Además, pareciera que el Tribunal Constitucional incluye también en la noción de tutela judicial efectiva el derecho al debido proceso. En efecto, los jueces constitucionales han señalado que "[e]ste derecho incluye el libre acceso a la jurisdicción, el derecho a obtener una resolución acerca de la pretensión deducida, el derecho a la ejecución de las resoluciones judiciales, la interdicción de la indefensión y el derecho al debido proceso, con la plena eficacia de todas las garantías que le son propias" ${ }^{26}$. Nosotros preferimos el concepto de acceso a la justicia, ya que es una

\footnotetext{
${ }^{25}$ Tribunal Constitucional de Chile: Requerimiento de inaplicabilidad presentado por Patricio Rodrigo Meneses Farias respecto del artículo 230, inciso primero, del Código Procesal Penal, en la causa RIT No 179-2005, RUC No 0510001570-08, del Juzgado de Garantía de San Fernando. Rol No 815-07. Sentencia de 19 de agosto de 2008. Considerando 9.

26 Tribunal Constitucional de Chile: Requerimiento de inaplicabilidad presentado por Patricio Rodrigo Meneses Farías respecto del artículo 230, inciso primero, del Código Procesal Penal, en la causa RIT No 179-2005, RUC No 0510001570-08, del Juzgado de Garantía de San Fernando. Rol No 815-07. Sentencia de 19 de agosto de 2008. Considerando $9^{\circ}$.
} 
noción más comprensiva, más incluyente y más englobante, que aquella de acceso a la jurisdicción. Esta última restringiría el principio, al acceso al servicio jurisdiccional, pero dejaría fuera el principio de acceso al goce y ejercicio del derecho mismo, esto es, a la realización judicial del derecho. También se prefiere el concepto de acceso a la justicia a aquel de tutela judicial efectiva, ya que este último podría entenderse restringiendo esta constelación normativa sólo al ámbito judicial, en circunstancias que el derecho de acceso a la justicia es más amplio.

2. Luego del análisis conceptual, conviene recordar como cuestión de principio, que el Tribunal Constitucional tiene la "responsabilidad de custodiar las garantías fundamentales de todos los habitantes de la Nación" 27 . Junto con lo anterior, en el caso Eduardo Sánchez, los jueces constitucionales han resaltado el rol primordial que juega la protección de los derechos humanos en la función jurisdiccional constitucional. De este modo, el órgano jurisdiccional constitucional ha señalado que "este órgano jurisdiccional, en ejercicio de su competencia para conocer y resolver las acciones de inaplicabilidad, ha sido llamado a custodiar la supremacía de la Constitución en aras de tutelar la adecuación de la actuación de los órganos del Estado a la esfera de su competencia, la dignidad de la persona humana y los derechos fundamentales" 28 . Además, el Tribunal Constitucional ha señalado que "las disposiciones contenidas en los artículos $1^{\circ}$ y $4^{\circ}$ de la Ley Fundamental se reconocen, a la vez, como normas jurídicas y como valores fundamentales del ordenamiento, que deben informar y guiar el actuar de todos los órganos del Estado"29. Aunque pareciera una declaración irrelevante, esta afirmación reviste la máxima importancia tanto en cuanto dichos preceptos contienen el principio de la dignidad humana y el principio democrático y, de acuerdo con los jueces constitucionales, dichos principios constituyen normas jurídicas y valores fundamentales del ordenamiento, que deben guiar su actuar. A mayor abundamiento,

\footnotetext{
${ }^{27}$ Tribunal Constitucional de Chile: Requerimiento de inaplicabilidad presentado por Aarón David Vásquez Muñoz, respecto del artículo 387, inciso segundo, del Código Procesal Penal, en causa RUC No 0600764824-1, del $8^{\circ}$ Juzgado de Garantía de Santiago. Rol No 986-2007. Sentencia de fecha 30 de enero de 2008. Considerando $2^{\circ}$.

${ }^{28}$ Tribunal Constitucional de Chile: Requerimiento de inaplicabilidad por inconstitucionalidad de Eduardo Sánchez Eyquem respecto de los artículos 230, inciso primero, 231, 237, incisos primero, segundo, tercero letra a), cuarto, quinto, séptimo y octavo, y 240, inciso segundo, del Código Procesal Penal, en el proceso por el delito de lesiones graves, RIT No 6118-2009, RUC No 0900447112-9, del Cuarto Juzgado de Garantía de Santiago. Rol No 1445-09. Sentencia de fecha 29 de enero de 2010. Considerando $25^{\circ}$.

29 Tribunal Constitucional de Chile: Requerimiento de inaplicabilidad presentado por Aarón David Vásquez Muñoz, respecto del artículo 387, inciso segundo, del Código Procesal Penal, en causa RUC No 0600764824-1, del $8^{\circ}$ Juzgado de Garantía de Santiago. Rol No 986-2007. Sentencia de fecha 30 de enero de 2008. Considerando $37^{\circ}$.
} 
los jueces constitucionales han indicado que "la dignidad humana, en cuanto valor (sic), a partir de su consagración en el artículo $1^{\circ}$, inciso primero, de la Ley Suprema, constituye la piedra angular de todos los derechos fundamentales que la Ley Suprema consagra" 30 .

3. Desde el punto de vista del acceso a la justicia, el propio Tribunal Constitucional, en el caso Rodrigo Meneses Farías, ha afirmado que "[u]no de los grandes valores que la Constitución consagra es el acceso al proceso, lato sensu, al expresar que toda sentencia de un órgano que ejerza jurisdicción debe fundarse en un proceso previo legalmente tramitado, correspondiendo al legislador establecer las garantías de un procedimiento e investigación racionales y justos. En este orden de regulaciones procesales, la Carta establece al Ministerio Público como el receptor natural de la noticia de la comisión del hecho punible, que, en consecuencia, en esta fase primaria de la investigación, es el destinatario de la acción por la cual se solicita investigar y posteriormente traspasar el conflicto al órgano jurisdiccional" 31 .

4. La Constitución no consagra de una manera precisa y clara el derecho al debido proceso. La Constitución sólo regula un contenido mínimo del debido proceso y, además, no lo define. A este respecto, el Tribunal Constitucional ha señalado, en el caso Aarón Vásquez, que "la Constitución no contiene una norma expresa que garantice, señalando con diáfana claridad, lo que la doctrina denomina "el debido proceso", sino que regula dos de sus aspectos, a saber:

a) Que toda sentencia de un órgano que ejerza jurisdicción, en este caso los tribunales penales competentes, ha de fundarse en un proceso previo legalmente tramitado. Ha de entenderse que el mismo se encuentra en tal hipótesis cuando en su etapa jurisdiccional de sustanciación se ajusta a la ley de procedimiento.

b) Precisa dicha norma que corresponderá al legislador establecer las garantías de un procedimiento racional y justo. En aplicación de tal disposición, los poderes colegisladores, elaboraron el texto del nuevo Código Procesal Penal.

Frente a esta realidad, esto es, no contar con una norma categórica que lo incorpore, este Tribunal Constitucional, en diversas sentencias, ha proporcionado

\footnotetext{
${ }^{30}$ Tribunal Constitucional de Chile: Requerimiento de inaplicabilidad por inconstitucionalidad del Juez Presidente del Juzgado de Familia de Pudahuel, señor Carlo Marcelo Casaula Mezzano respecto del artículo 206 del Código Civil, en la causa RIT No C-111-2009, seguida por investigación/reclamación de paternidad, caratulada "Muñoz con Muñoz". Rol No 1340-2009. Sentencia de fecha 29 de septiembre de 2009. Considerando 9.

${ }^{31}$ Tribunal Constitucional de Chile: Requerimiento de inaplicabilidad presentado por Patricio Rodrigo Meneses Farías respecto del artículo 230, inciso primero, del Código Procesal Penal, en la causa RIT No 179-2005, RUC No 0510001570-08, del Juzgado de Garantía de San Fernando. Rol No 815-07. Sentencia de 19 de agosto de 2008. Considerando $6^{\circ}$.
} 
elementos para precisar el concepto de debido proceso, que sustenta en un conjunto de disposiciones de la Constitución, entre las cuales se incluye el artículo 19 número $3^{\circ}$, donde, por cierto, no fue definido" 32 .

5. Pero, además, el Tribunal Constitucional ha señalado que "nuestra Constitución consagra, sin denominarlo así, el invocado derecho a la tutela judicial efectiva, en el inciso primero del artículo 19 , numeral $3^{\circ}$, y en las normas que lo complementan, al reconocerse con fuerza normativa, que todas las personas son iguales en el ejercicio de los derechos, lo que comprende, en nuestro medio, su igualdad de posibilidades ante los órganos jurisdiccionales, incluyendo, en primer término, el derecho a la acción, sin el cual quedaría amenazado e incompleto" ${ }^{33}$. Entonces, no nos queda claro cuál es el derecho que nuestra Constitución consagra, o el derecho al debido proceso o el derecho a la tutela judicial efectiva, y tampoco el tribunal nos deja claro cuál es la relación entre estos conceptos.

6. El Tribunal Constitucional nos ha proporcionado una propuesta de definición de 'debido proceso' indicando que "por debido proceso se entiende aquel que cumple integralmente la función constitucional de resolver conflictos de intereses de relevancia jurídica con efecto de cosa juzgada, protegiendo y resguardando, como su natural consecuencia, la organización del Estado, las garantías constitucionales y, en definitiva, la plena eficacia del Estado de Derecho. A este respecto, el debido proceso cumple una función dentro del sistema, en cuanto garantía del orden jurídico, manifestado a través de los derechos fundamentales que la Constitución le asegura a las personas. Desde esta perspectiva el imperio del derecho y la resolución de conflictos mediante el proceso son una garantía de respeto por el derecho ajeno y la paz social. En síntesis, el debido proceso, más allá de consagrar los derechos de los litigantes, y el poder deber del juez en la forma que el constituyente ha establecido para eliminar la fuerza en la solución de los conflictos, genera un medio idóneo para que cada cual pueda obtener la solución de sus conflictos a través de su desenvolvimiento" ${ }^{34}$.

${ }^{32}$ Tribunal Constitucional de Chile: Requerimiento de inaplicabilidad presentado por Aarón David Vásquez Muñoz, respecto del artículo 387, inciso segundo, del Código Procesal Penal, en causa RUC No 0600764824-1, del $8^{\circ}$ Juzgado de Garantía de Santiago. Rol No 986-2007. Sentencia de fecha 30 de enero de 2008. Considerando $8^{\circ}$.

${ }^{33}$ Tribunal Constitucional de Chile: Requerimiento de inaplicabilidad presentado por Patricio Rodrigo Meneses Farías respecto del artículo 230, inciso primero, del Código Procesal Penal, en la causa RIT No 179-2005, RUC No 0510001570-08, del Juzgado de Garantía de San Fernando. Rol No 815-07. Sentencia de 19 de agosto de 2008. Considerando $10^{\circ}$.

${ }^{34}$ Tribunal Constitucional de Chile: Requerimiento de inaplicabilidad presentado por Aarón David Vásquez Muñoz, respecto del artículo 387, inciso segundo, del Código Procesal Penal, en causa RUC No 0600764824-1, del $8^{\circ}$ Juzgado de Garantía de Santiago. Rol No 986-2007. Sentencia de fecha 30 de enero de 2008. Considerando $17^{\circ}$. 
7. El Tribunal Constitucional incluye lógicamente, dentro del debido proceso, el derecho de acción así como el derecho de defensa. "Desde una perspectiva constitucional, y de derechos fundamentales, el debido proceso se traduce no sólo en las garantías del imputado, sino también en el derecho a acceder a la justicia de la víctima para perseguir la reparación del mal causado y el castigo a los culpables, a través de los medios establecidos en la ley procesal y traducidos en el proceso en contra del imputado" 35 .

8. ¿Cuáles son los elementos de un procedimiento racional y justo? El Tribunal Constitucional ha desarrollado estos elementos en reiteradas ocasiones, señalando que "el derecho a un proceso previo, legalmente tramitado, racional y justo, que la Constitución asegura a todas las personas, debe contemplar las siguientes garantías: la publicidad de los actos jurisdiccionales, el derecho a la acción, el oportuno conocimiento de ella por la parte contraria, el emplazamiento, adecuada asesoría y defensa con abogados, la producción libre de pruebas conforme a la ley, el examen y objeción de la evidencia rendida, la bilateralidad de la audiencia, la facultad de interponer recursos para revisar las sentencias dictadas por tribunales inferiores" 36 . Y la Corte Suprema ha agregado como componentes de este principio "el pronunciamiento de los fallos dentro de los plazos legales previstos y la fundamentación de ellos en el régimen jurídico vigente o, en su defecto, en los principios generales del derecho y equidad natural"37. Además, la Corte Suprema ha complementado el acceso a la justicia con elementos adicionales, señalando que "Durante el proceso, toda persona tiene derecho, en plena igualdad, a las siguientes garantías mínimas: a) derecho del inculpado de ser asistido gratuitamente por el traductor o intérprete, si no comprende o no habla el idioma del juzgado o tribunal; b) comunicación previa y detallada al inculpado de la acusación formulada; c) concesión al inculpado del tiempo y de los medios adecuados para la preparación de su defensa; d) derecho del inculpado de defenderse personalmente o de ser asistido por un defensor de su elección y de comunicarse libre y privada-

\footnotetext{
${ }^{35}$ Tribunal Constitucional de Chile: Requerimiento de inaplicabilidad presentado por Aarón David Vásquez Muñoz, respecto del artículo 387, inciso segundo, del Código Procesal Penal, en causa RUC No 0600764824-1, del $8^{\circ}$ Juzgado de Garantía de Santiago. Rol No 986-2007. Sentencia de fecha 30 de enero de 2008. Considerando $17^{\circ}$.

${ }^{36}$ Tribunal Constitucional de Chile: Requerimiento de inaplicabilidad presentado por Aarón David Vásquez Muñoz, respecto del artículo 387, inciso segundo, del Código Procesal Penal, en causa RUC No 0600764824-1, del $8^{\circ}$ Juzgado de Garantía de Santiago. Rol No 986-2007. Sentencia de fecha 30 de enero de 2008. Considerando $27^{\circ}$.

${ }^{37}$ Corte Suprema de Chile: Caso Gabriela de Castro Espinoza con Servicio de Impuestos Internos. Recurso de Inaplicabilidad. Rol 3643-2000; Corte Suprema de Chile: Iturriaga Neumann, Eduardo. Extradición pasiva. Rol No 3-2000. Sentencia de fecha 3 de octubre de 2000. Considerando $16^{\circ}$.
} 
mente con su defensor; e) derecho irrenunciable de ser asistido por un defensor proporcionado por el Estado, remunerado o no según la legislación interna, si el inculpado no se defendiere por sí mismo ni nombrare defensor dentro del plazo establecido por la ley; f) derecho de la defensa de interrogar a los testigos presentes en el tribunal y de obtener la comparecencia, como testigos o peritos, de otras personas que puedan arrojar luz sobre los hechos; g) derecho a no ser obligado a declarar contra sí mismo ni a declararse culpable, y h) derecho de recurrir del fallo ante el juez o tribunal superior" 38 .

9. Junto con lo anterior, los jueces constitucionales han destacado la doble dimensión de la tutela judicial efectiva, que no es sino una concretización de la doble dimensión de los derechos humanos. En efecto, "el derecho a la tutela judicial efectiva tiene una doble dimensión, por una parte adjetiva, respecto de los otros derechos e intereses, y por la otra, sustantiva, pues es en sí mismo un derecho fundamental es autónomo, que tiene por finalidad que las personas accedan al proceso como medio ordinario de resolución de los conflictos jurídicos, lo que resulta un presupuesto mínimo de todo Estado de derecho"39. El Ministro Colombo Campbell, en su voto disidente en la sentencia Rol No 1445-09, agrega que todo lo anteriormente dicho "da eficacia al principio de acceso a la jurisdicción, sin el cual todo el aparato del sistema jurídico debe ser visto como incompleto" 40 .

10. El derecho de acceso a la justicia, obviamente, es un derecho de todos los individuos, por lo tanto, en materia penal, pertenece tanto al imputado como a la víctima. En este sentido, los jueces constitucionales han señalado que "el debido proceso se traduce no sólo en las garantías del imputado, sino también en el derecho a acceder a la justicia de la víctima para perseguir la reparación del mal causado y el castigo a los culpables" ${ }^{\prime 1}$.

\footnotetext{
${ }^{38}$ Corte Suprema de Chile: Iturriaga Neumann, Eduardo. Extradición pasiva. Rol No 3-2000. Sentencia de fecha 3 de octubre de 2000. Considerando $17^{\circ}$.

39 Tribunal Constitucional de Chile: Requerimiento de inaplicabilidad presentado por Patricio Rodrigo Meneses Farias respecto del artículo 230, inciso primero, del Código Procesal Penal, en la causa RIT No 179-2005, RUC No 0510001570-08, del Juzgado de Garantía de San Fernando. Rol No 815-07. Sentencia de 19 de agosto de 2008. Considerando $10^{\circ}$.

${ }^{40}$ Tribunal Constitucional de Chile: Requerimiento de inaplicabilidad por inconstitucionalidad de Eduardo Sánchez Eyquem respecto de los artículos 230, inciso primero, 231, 237, incisos primero, segundo, tercero letra a), cuarto, quinto, séptimo y octavo, y 240, inciso segundo, del Código Procesal Penal, en el proceso por el delito de lesiones graves, RIT No 6118-2009, RUC No 0900447112-9, del Cuarto Juzgado de Garantía de Santiago. Rol No 1445-09. Sentencia de fecha 29 de enero de 2010. Voto disidente del Ministro señor Juan Colombo Campbell. Considerando $12^{\circ}$.

${ }^{41}$ Tribunal Constitucional de Chile: Requerimiento de inaplicabilidad presentado por Patricio Rodrigo Meneses Farías respecto del artículo 230, inciso primero, del Código Procesal Penal, en la causa RIT No 179-2005, RUC No 0510001570-08, del Juzgado de Garantía de San Fernando. Rol No 815-07. Sentencia de 19 de agosto de
} 
11. Concretamente, en el caso de la acción de inaplicabilidad presentada por el juez Rondini Fernández-Dávila respecto del artículo 149 del Código Procesal Penal, el voto disidente deja claramente de manifiesto su contradicción con la Constitución, pero sobre todo con los fines y valores constitucionales. En efecto, el voto menciona que de aplicarse el precepto impugnado "el mismo produciría efectos contrarios a lo dispuesto en la letra e) del numeral $7^{\circ}$ del artículo 19 de la Carta Fundamental. En esa norma, la Constitución asegura que la libertad del imputado procederá, a menos que la detención o prisión preventiva sea considerada por el juez como necesaria para alguno de los tres bienes que la propia norma señala. En cambio, si llegara a aplicarse la disposición legal cuestionada, la privación de libertad del imputado se mantendrá aun cuando el juez expresamente haya resuelto que no la considera necesaria. La contradicción de ambas normas es palmaria y la Carta Fundamental no autoriza que un imputado puesto a disposición de un juez permanezca privado de libertad por la sola voluntad de un fiscal del Ministerio Público”². La norma del artículo 149 del Código Procesal Penal responde a una lógica represora de seguridad ciudadana que restringe los derechos fundamentales en forma contraria al espíritu y a los valores constitucionales y las normas internacionales. Una de las funciones jurídicas de los derechos humanos es precisamente proteger al individuo de los abusos del poder, cualquiera que éste sea. Además, en este caso, los jueces constitucionales no utilizaron el principio pro homine, útil de interpretación al que sí han ocurrido en otras ocasiones ${ }^{43}$.

\section{VII. ¿CUÁL HA SIDO EL FUNDAMENTO JURÍDICO PRINCIPAL DE PARTE \\ del Tribunal Constitucional para no objetar, SEGÚN LA CONSTITUCIÓN, EL DISEÑO PROCESAL PENAL?}

1. En el caso de Aarón Vásquez, el Tribunal Constitucional recurre al denominado principio de autonomía. Dice que "la esfera de autonomía comprende,

\footnotetext{
2008. Considerando $12^{\circ}$; Vid. también Tribunal Constitucional de Chile: Requerimiento de inaplicabilidad presentado por Aarón David Vásquez Muñoz, respecto del artículo 387, inciso segundo, del Código Procesal Penal, en causa RUC No 0600764824-1, del $8^{\circ}$ Juzgado de Garantía de Santiago. Rol No 986-2007. Sentencia de fecha 30 de enero de 2008.

${ }^{42}$ Tribunal Constitucional de Chile: Requerimiento de inaplicabilidad del Juez del Juzgado de Garantía de Puerto Montt respecto del artículo 149, inciso segundo, del Código Procesal Penal, en la causa RIT No 37982008, RUC No 0800363671-3, seguida en contra de César Uribe Villegas por el delito de robo con violencia. Rol No 1065-2008. Sentencia de fecha 18 de diciembre de 2008. Voto disidente de los Ministros Mario Fernández Baeza y Jorge Correa Sutil. Considerando $2^{\circ}$.

${ }^{43}$ Tribunal Constitucional Chileno: Requerimiento de inconstitucionalidad deducido en contra de algunas disposiciones de las "Normas Nacionales sobre Regulación de la Fertilidad", aprobadas por el Decreto Supremo No 48, de 2007, del Ministerio de Salud. Rol No 740-2008. Sentencia de fecha 18 de abril de 2008.
} 
básicamente, el conjunto de apreciaciones de mérito y oportunidad que llevan al legislador a la adopción de una u otra fórmula normativa. Sólo cuando el legislador excede su ámbito de competencia, infringiendo los márgenes contemplados en la Carta Fundamental, el Tribunal Constitucional puede intervenir para reparar los vicios de inconstitucionalidad en que éste haya incurrido" ${ }^{44}$. En el caso de la acción de inaplicabilidad presentada por el juez Rondini Fernández-Dávila, los jueces constitucionales reiteraron esta misma idea. En efecto, "el Tribunal Constitucional es el principal órgano encargado de velar por que la ley, o más bien -en esta sede- su aplicación a un caso concreto, efectivamente, no vulnere los límites constitucionales, lo que significa, a la vez, la garantía de cierta esfera de autonomía del legislador -como depositario de la voluntad democrática-, que comprende, básicamente, el conjunto de apreciaciones de política, conveniencia y oportunidad que lo llevan a la adopción de una u otra fórmula normativa orgánica. De este modo, como se ha consignado por esta Jurisdicción Constitucional, sólo cuando el Congreso Nacional excede su ámbito de atribuciones, infringiendo los márgenes contemplados en el texto, principios o valores esenciales de la Carta Fundamental, o violente el proceso de formación de la ley, el Tribunal Constitucional puede intervenir para reparar los vicios de inconstitucionalidad -de forma o fondo- en que éste haya incurrido" ${ }^{45}$.

2. El Tribunal adelanta que no puede pronunciarse porque "el Tribunal no legisla ni administra, ni entra a calificar la bondad de las disposiciones legales o administrativas. Sólo debe resolver si se ajustan o no a las normas, valores y principios constitucionales. De una parte, debe velar por que la ley o el decreto no vulnere los límites constitucionales y de otra no puede inmiscuirse en la esencia del ejercicio de las funciones públicas que le corresponden al Congreso Nacional, al Presidente de la República o a los Tribunales de Justicia. En el ejercicio de esta facultad, el legislador se encuentra sujeto al marco que fija la propia Carta Fundamental y el Tribunal Constitucional es el principal órgano encargado de velar porque la ley efectivamente no vulnere los límites constitucionales”46. Esta afirmación llama, al

\footnotetext{
${ }^{44}$ Tribunal Constitucional de Chile: Requerimiento de inaplicabilidad presentado por Aarón David Vásquez Muñoz, respecto del artículo 387, inciso segundo, del Código Procesal Penal, en causa RUC No 0600764824-1, del $8^{\circ}$ Juzgado de Garantía de Santiago. Rol No 986-2007. Sentencia de fecha 30 de enero de 2008. Considerando $16^{\circ}$.

${ }^{45}$ Tribunal Constitucional de Chile: Requerimiento de inaplicabilidad del Juez del Juzgado de Garantía de Puerto Montt respecto del artículo 149, inciso segundo, del Código Procesal Penal, en la causa RIT No 3798-2008, RUC No 0800363671-3, seguida en contra de César Uribe Villegas por el delito de robo con violencia. Rol No 10652008. Sentencia de fecha 18 de diciembre de 2008. Considerando $35^{\circ}$.

${ }^{46}$ Tribunal Constitucional de Chile: Requerimiento de inaplicabilidad presentado por Aarón David Vásquez Muñoz, respecto del artículo 387, inciso segundo, del Código Procesal Penal, en causa RUC No 0600764824-1,
} 
menos, una reflexión. En este caso, nadie pide a los jueces constitucionales que se pronuncien sobre la bondad o la oportunidad en la elección legislativa del modelo procesal penal, pero sí se le solicita contrastar normas determinadas del proceso penal aplicables a casos concretos con la Constitución, de manera de determinar su compatibilidad constitucional.

3. A mayor abundamiento, el Tribunal Constitucional nos señala que "dentro de los principios informadores del proceso penal, se encuentra la configuración del mismo en base a la única o a la doble instancia, opción de política legislativa que corresponde al legislador decidir, en el marco de las reservas legales específicas de las garantías de legalidad del proceso y del racional y justo procedimiento, contenidas en el artículo 19 número 3 de la Carta Fundamental, que deben ser entendidas, además, limitadas por la garantía genérica de respeto a los derechos fundamentales como límite al poder estatal, establecida en la primera parte del inciso segundo del artículo $5^{\circ}$ de la misma" ${ }^{37}$.

4. En este contexto, el propio Tribunal Constitucional señala que "los órganos colegisladores fueron quienes tomaron, en ese momento, la decisión acerca de que el mejor sistema para contar con un debido proceso penal fue el de establecer un juicio oral en única instancia. En tales circunstancias, se cumplió con los presupuestos necesarios del debido proceso" ${ }^{48}$. Para nuestro gusto, la conclusión se extrae muy rápidamente. Estamos de acuerdo en que la elección corresponde al legislador, pero el legislador democrático se encuentra sometido, y en eso -inter alia- consiste el constitucionalismo contemporáneo, al respeto de la dignidad humana y de los derechos humanos. La tan manida legitimidad democrática no puede erguirse en un rompehielos que justifique abrir brechas en el terreno de los derechos humanos. Veamos cómo se alzan frente al legislador, y frente a todos los poderes del Estado, los valores constitucionales fundamentales. Veamos también, cómo se operacionalizan los valores y principios fundamentales en el constitucionalismo contemporáneo.

del $8^{\circ}$ Juzgado de Garantía de Santiago. Rol No 986-2007. Sentencia de fecha 30 de enero de 2008. Considerando $16^{\circ}$.

${ }^{47}$ Tribunal Constitucional de Chile: Requerimiento de inaplicabilidad presentado por Aarón David Vásquez Muñoz, respecto del artículo 387, inciso segundo, del Código Procesal Penal, en causa RUC No 0600764824-1, del $8^{\circ}$ Juzgado de Garantía de Santiago. Rol No 986-2007. Sentencia de fecha 30 de enero de 2008. Considerando $26^{\circ}$.

${ }^{48}$ Tribunal Constitucional de Chile: Requerimiento de inaplicabilidad presentado por Aarón David Vásquez Muñoz, respecto del artículo 387, inciso segundo, del Código Procesal Penal, en causa RUC No 0600764824-1, del $8^{\circ}$ Juzgado de Garantía de Santiago. Rol No 986-2007. Sentencia de fecha 30 de enero de 2008. Considerando $17^{\circ}$. 


\section{ACCESO A LA JUSTICIA Y SOCIEDAD DEMOCRÁTICA:}

\section{PRECISIÓN CONCEPTUAL}

1. Cabe destacar la conceptualización moderna de la noción de Constitución ya que de acuerdo con ello, la interpretación constitucional se efectúa en función de los fines constitucionales expresados en los valores y principios que ella porta. En efecto, como ha señalado Schneider "la Constitución posee, más bien, el carácter de un amplio modelo, es un modelo de vida para la comunidad política orientado hacia el futuro [...] De ello resulta la orientación finalista del derecho constitucional [...] Tales objetivos de la Constitución son la realización de una humanidad real en la convivencia social, el respeto de la dignidad humana, el logro de la justicia social sobre la base de la solidaridad y el marco de la igualdad y de la libertad, la creación de condiciones socioeconómicas para la libre autorrealización y emancipación humana, así como el desarrollo de una conciencia política general de responsabilidad democrática" ${ }^{49}$. En este mismo sentido Carbonell se refiere a la Constitución como una aspiración de futuro, como una especie de utopía concreta o carta de navegación ${ }^{50}$. Y, por su parte, Gee and Weber se refieren a la Constitución como modelo ${ }^{51}$. De aquí la importancia del proceso de constitucionalización del ordenamiento jurídico, ya que esta aspiración de futuro impregna todo el ordenamiento. Para Guastini "un ordenamiento jurídico constitucionalizado se caracteriza por una constitución extremadamente invasora, entrometida, capaz de condicionar tanto la legislación como la jurisprudencia y el estilo doctrinal, la acción de los actores políticos así como las relaciones sociales" ${ }^{52}$. Este modelo de sociedad -que es la Constitución- que se nutre del pasado y del presente, pero que también ofrece una potente visión de futuro, es una Constitución esencialmente portadora de principios y valores fundamentales. Así, Stintzing expresa que la Constitución debería estar abierta a los desarrollos sociales, ya que de otro modo su legitimidad estaría en peligro ${ }^{53}$. Además, Ferrajoli alude al nuevo paradigma del constitucionalismo del siglo XX y al valor de la Constitución como un con-

\footnotetext{
${ }^{49}$ SChneider, Hans-Peter: Democracia y Constitución. Madrid, CEC, 1991, p. 49.

${ }^{50}$ Carbonell, Miguel: "La Constitución en el tiempo: una nota", en Cienfuegos Salgado, David y López Olivera, Miguel Alejandro (Coord.): Estudios en Homenaje a don Jorge Fernández Ruiz. Derecho Constitucional y Politica. UNAM, IIJ, Madrid, 2005, p. 105.

${ }^{51}$ Gee, Graham and Webber, Grégoire C.: "What Is a Political Constitution?", in Oxford Journal of Legal Studies, Vol. 30, No 2 (2010), pp. 273-299.

${ }^{52}$ Guastini, Riccardo: Lezioni di Teoria Costituzionale. Torino, G. Giappichelli editore, 2001, p. 204.

${ }^{53}$ STINTZING, Heike: "Constitutional Values and Social Change: The Case of German Marital and Family Law", in International Journal of Law, Policy and the Family, num. 13 (1999), pp. 132-146.
} 
junto de normas sustanciales que garantizan la división de poderes y los derechos fundamentales de todos. En este sentido de la Constitución, Ferrajoli se refiere a la idea del derecho sobre el derecho 'en forma de límite y vínculo jurídico a la producción jurídica'54. Zagrebelsky ha afirmado a este respecto que "es preciso darse cuenta de que 'el derecho por reglas' del Estado de derecho decimonónico era algo cualitativamente distinto al 'derecho por principios' del Estado constitucional contemporáneo y de que este cambio estructural del derecho tiene que comportar necesariamente consecuencias muy serias también para la jurisdicción" ${ }^{55}$. En este moderno derecho por principios juegan un rol fundamental los derechos humanos constituyendo una de las piedras angulares de lo que Ferrajoli denomina 'constitucionalismo cosmopolita ${ }^{56}$. Esta misma idea es la que afirma Weiler cuando señala que sujetar la legislatura elegida democráticamente a los tribunales y a las normas de un "Higher Law" de los derechos humanos fundamentales, a pesar de la imagen contra mayoritaria, es crecientemente considerada como un fundamento adicional a la gobernanza democrática ${ }^{57}$.

2. Todas las razones anteriores, como ha mencionado Zagrebelsky, deberían tener un impacto en el ejercicio de la jurisdicción e interpretación constitucional. En el ámbito de la interpretación constitucional se habla de interpretación constitucional propiamente tal o de construcción constitucional. Interpretación constitucional, en general, es el proceso por el cual se le asigna significado a las palabras en la Constitución, para permitir o hacer que las decisiones jurídicas se encuentren justificadas por esta interpretación. Algunos autores distinguen entre 'interpretación' constitucional, esto es, la asignación de significado basado en los significados de otros usos del término que se encuentran en conocimiento de los redactores y lectores del texto. Y 'construcción' constitucional, esto es, inferir el significado desde un conjunto más amplio de evidencias o elementos, tales como la estructura del texto completo a partir del cual se puede discernir la función de varias partes, o bien, la discusión por los redactores o aquellos que lo

\footnotetext{
${ }^{54}$ Ferrajoli, Luigi: Diritti Fondamentali. Un dibattito teorico. A cura di Ermanno Vitale. Bari, editore Laterza, 2001, p. 35.

${ }^{55}$ Zagrebelsky, Gustavo: El derecho dúctil. Ley, derechos, justicia. Traducción de Marina Gascón, Madrid, Trotta, 1995, pp. 112.

${ }^{56}$ El constitucionalismo cosmopolita "ya estaría prefigurado en la actualidad (al menos en forma embrionaria) en textos internacionales como la Carta de la ONU y los pactos y declaraciones internacionales de derechos humanos". Ferrajoli, Luigi: "Razones jurídicas del pacifismo", en Pisarello, Gerardo (ed.), Madrid, Trotta, 2004, pp. 81 y ss.

57 Weiler, J.H.H.: "Human Rights, Constitutionalism and Integration: Iconography and Fetishism", en International Law FORUM du droit international, num. 3 (2001), pp. 227-238.
} 
han ratificado durante el debate que condujo a la adopción. Además, se pueden considerar el conjunto de controversias en las que se encontró sumido el término y que muestra las preocupaciones y expectativas de los redactores y aquellos que ratificaron el texto. Del mismo modo, diferentes alternativas de elaboración del término o frase y sus significados aceptados o rechazados en diferentes etapas del desarrollo de la redacción y adopción del texto. Finalmente, se puede recurrir a indicaciones de significado que pueden ser inferidos de lo que no se dijo, entre otros métodos de análisis inductivo. Sin embargo, uno de los elementos más trascendentes y englobantes de la interpretación general es la lógica, la coherencia en la interpretación y el rechazo del absurdo. En la interpretación constitucional, la interpretación conforme con los valores y principios constitucionales es esencial. Por eso es importante que el juez constitucional identifique los valores y principios constitucionales fundamentales.

3. En este contexto de identificación de los valores y principios constitucionales fundamentales del ordenamiento, el profesor Friedmann clasifica los principios generales de derecho en tres categorías principales: 1) principios de aproximación e interpretación a las relaciones jurídicas de todo tipo (máximas legales o principios romanistas); 2) estándares mínimos de justicia procedural; 3) principios sustantivos de derecho suficientemente amplios y firmemente reconocidos en los sistemas legales más relevantes del mundo como para ser considerados como principios jurídicos internacionales. En 1969, el profesor Friedmann señaló correctamente que existe un amplio consenso sobre los estándares mínimos del debido proceso. "Entre estos principios se encuentran: que nadie debería estar sujeto a arresto o detención ilimitada sin un proceso judicial; que no debe haber identidad entre el fiscal y el juez; y que cualquier acusado debe tener la oportunidad de ser justamente oído. Estos principios están incorporados no sólo en los códigos de las naciones occidentales sino también [...] en la Declaración Universal de Derechos Humanos de Naciones Unidas de 1948, y en los Convenios de Derechos Humanos más recientes. Ellos pueden ser justamente descritos como principios generales de justicia procesal internacionalmente aplicables" ${ }^{58}$.

4. Por su parte, el profesor Simma ha señalado que "no importa cuánto progreso es apreciado a nivel internacional, la implementación y el reconocimiento efectivo de las normas internacionales a nivel interno continúa a ser vital para la realización total e integral de los derechos humanos. Mientras la obligación internacional del Estado de observar las normas de derechos humanos vincula a todos los poderes del Estado, no solamente al poder judicial, los tribunales están bien

\footnotetext{
${ }^{58}$ Friedmann, Wolfgang: "General Course in Public International Law", 127, Recueil des Cours de l'Académie de Droit International de La Haye (1969-II) 39-246, at 153.
} 
ubicados para jugar un rol clave en la aplicación de las normas internacionales de derechos humanos a nivel interno" 59 . El propio profesor Simma ha indicado que "a diferencia de otros países como Alemania, los tribunales chilenos no disfrutan de un poder de revisión judicial amplio desde el momento en que la Constitución chilena no garantiza un derecho a un recurso judicial en todos los casos de violación de los derechos individuales por las autoridades públicas" ${ }^{60}$. En este sentido es conveniente reiterar lo que ha sostenido la Corte Interamericana de Derechos Humanos en el sentido de que "[p]roporcionar tales recursos es un deber jurídico de los Estados"61. Es conveniente recordar aquí que nosotros sostenemos que la restricción de la procedencia del recurso de protección en la Constitución chilena sólo a algunos derechos fundamentales es incompatible con el derecho de acceso a la justicia, tal como está garantizado en la Convención Americana sobre Derechos Humanos.

5. En esta misma línea, coincidiendo con la idea del profesor Friedmann en el sentido de los principios generales de justicia procesal internacionalmente aceptados, el profesor Francioni ha indicado que una parte integral del estándar mínimo de justicia es el principio de acceso a la justicia. Francioni asume un concepto amplio de acceso a la justicia, entendido como el derecho del individuo a obtener la protección de la ley y la disponibilidad de recursos ante un tribunal o ante otro mecanismo equivalente de protección judicial o cuasi-judicial. El profesor del Instituto Europeo de Florencia señala que este tipo de protección es un requisito sine qua non para cualquier tipo de democracia constitucional donde el estado de derecho y la independencia de los tribunales, más bien que la benevolencia del gobernante, proporcionan garantías fundamentales a los derechos individuales y libertades ${ }^{62}$. Quizás, los planteamientos del profesor Friedmann y Francioni confluyen con las propuestas del profesor Simma relativas a la existencia de un

\footnotetext{
59 Simma, Bruno, Khan, Daniel-Erasmus, Zöckler, Markus and Geiger, Rudolf: "The Role of German Courts in the Enforcement of International Human Rights", in Conforti, Benedetto and Francioni, Francesco (eds.): Enforcing International Human Rights in Domestic Courts (Martinus Nijhoff Publishers, The Hague) 71-109, 1997 at 71.

${ }^{60}$ Simma, Bruno, Khan, Daniel-Erasmus, ZöCKLer, Markus and Geiger, Rudolf: "The Role of German Courts in the Enforcement of International Human Rights", in Conforti, Benedetto and Francioni, Francesco (eds.): Enforcing International Human Rights in Domestic Courts (Martinus Nijhoff Publishers, The Hague) 71-109, 1997 at 72.

${ }^{61}$ Corte I.D.H.: Caso Velásquez Rodríguez vs. Honduras. Fondo. Sentencia de 29 de julio de 1988. Serie C No 4, par. 62.

${ }^{62}$ Francioni, Francesco: "Access to Justice, Denial of Justice and International Investment Law", en European Journal of International Law, vol 20, num. 3 (2009), pp. 729-747.
} 
criterio referido a un mínimo de cultura jurídica, del cual formaría parte el derecho de acceso a la justicia ${ }^{63}$.

6. El profesor Conforti ha señalado que "una vez que las convenciones internacionales de derechos humanos han sido ratificadas por el Estado y han adquirido validez formal en el sistema legal interno luego de su publicación (como ocurre en países con una tradición monista), o debido a la dictación de un estatuto ad hoc (como ocurre en países con una tradición dualista) ellos deben necesariamente ser aplicados por los tribunales. Ningún obstáculo, relacionado a su origen internacional, puede impedir su aplicación. Desafortunadamente, esto no es siempre lo que ocurre, principalmente debido a la falta de familiaridad de los tribunales con el Derecho Internacional" ${ }^{64}$. Quizás deberíamos reflexionar también la posibilidad de una cierta enemistad o falta de convicción seria por parte del juez nacional con respecto al Derecho Internacional y, sin embargo, el Derecho Internacional no es más -pero tampoco menos- que eso, Derecho aceptado como obligatorio por el Estado y directamente aplicable por el juez nacional. El Derecho Internacional de los Derechos Humanos debería ser aplicable con prioridad en el orden interno, cuando otorga una protección del individuo, comunidades y pueblos creciente o mayor que el derecho interno. En este contexto, la precisión del profesor Decaux es pertinente en el sentido que "la posición del juez nacional con respecto al derecho internacional y su evolución reciente en el área de los derechos humanos sólo puede ser entendida ubicando la noción de soberanía en el centro del debate"65.

7. Desde el punto de vista de los tribunales extranjeros y la experiencia comparada, en Alemania, el profesor Simma ha señalado que "[e]l Tribunal Constitucional Federal alemán (Bundesverfassungsgericht) ejerce el poder para revisar la constitucionalidad de la legislación nacional y puede declarar la nulidad de la legislación inconstitucional". Finalmente, uno podría esperar que los tribunales

\footnotetext{
${ }^{63}$ Con el fin de evitar el continuo conflicto de argumentos y posiciones entre positivistas y partidarios del derecho natural, "tal vez, sería más fácil simplemente argumentar que nuestro concepto del derecho requiere que las reglas legales deben cumplir con el criterio de un mínimo de cultura jurídica, un estándar que no ha sido alcanzado por el régimen de frontera de la República Democrática Alemana". Simma, Bruno, Khan, Daniel-Erasmus, ZÖCKLER, Markus and GeIGER, Rudolf: "The Role of German Courts in the Enforcement of International Human Rights", in CONFORTI, Benedetto and FranCIONI, Francesco (eds.): Enforcing International Human Rights in Domestic Courts (Martinus Nijhoff Publishers, The Hague) 71-109, 1997 at 107.

${ }^{64}$ Conforti, Benedetto: "National Courts and the International Law of Human Rights", in Conforti, Benedetto and Francioni, Francesco (eds.): Enforcing International Human Rights in Domestic Courts (Martinus Nijhoff Publishers, The Hague) 3-14, 1997 at 7.

${ }^{65}$ Decaux, Emmanuel: "A Report on the Role of French Judges in the Enforcement of International Human Rights", in Conforti, Benedetto and Francioni, Francesco (eds.): Enforcing International Human Rights in Domestic Courts (Martinus Nijhoff Publishers, The Hague) 111-134, 1997 at 111.
} 
alemanes jugaran un rol clave en la implementación del derecho internacional de los derechos humanos porque ellos han demostrado un fuerte compromiso en la protección de los derechos constitucionales del individuo. Desde el momento que los tribunales alemanes, especialmente el tribunal constitucional alemán, aplica los derechos constitucionales individuales contra las acciones del legislador y del gobierno de una manera efectiva, uno podría esperar que ellos también usaran su poder para la aplicación de los derechos humanos internacionales con igual vigor" 66 .

8. Por su parte, la Corte de Casación italiana, en una decisión de 15 de mayo de 1989, sobre el principio de inmunidad, consideró que tenía jurisdicción en todas las situaciones donde el empleado es un local nacional y la disputa concierne aspectos financieros de la relación laboral. De acuerdo con la Corte de Casación, esta posición no sólo se conforma con una creciente tendencia de las últimas décadas a restringir las inmunidades, sino también ha sido adoptada para solucionar una creciente dificultad, un problema creciente en los esfuerzos para reconciliar satisfactoriamente dos necesidades divergentes: "a) asegurar el respeto por los Estados extranjeros; b) proteger los derechos de los nacionales dándoles acceso a los tribunales nacionales, lo cual es esencial para proporcionarles un medio práctico para obtener justicia" ${ }^{67}$. Esta decisión judicial es una manifestación de una tendencia creciente a hacer prevalecer el principio de acceso a la justicia, incluso, frente a aquellas excepciones fuertemente arraigadas en el derecho.

9. Además, aparece interesante resaltar el caso de los Guardias del Muro de Berlín, ante la Corte Europea de Derechos Humanos (en adelante, la Corte EDH). La Corte se refiere a su jurisprudencia sobre juicios de la posguerra que tratan de los crímenes nazis. En estos juicios, los tribunales nacionales sostuvieron repetidamente que las leyes del período nazi eran nulas si ellas constituían violaciones graves de los principios fundamentales de justicia y humanidad, los cuales deben ser respetados por todos los Estados, sin importar su forma de gobierno. En el caso de los guardias del muro, la Corte EDH proporcionó nuevos fundamentos definiendo el contenido de estos principios fundamentales con la ayuda del Derecho Internacional de los Derechos Humanos. La Corte enfatizó por primera

\footnotetext{
${ }^{66}$ Simma, Bruno, Khan, Daniel-Erasmus, Zöckler, Markus and Geiger, Rudolf: "The Role of German Courts in the Enforcement of Intenational Human Rights", in Conforti, Benedetto and FranCiOni, Francesco (eds.): Enforcing International Human Rights in Domestic Courts (Martinus Nijhoff Publishers, The Hague) 71-109, 1997 at 72.

${ }^{67}$ Foro It., 1989, I, col. 2466; CONFORTI, Benedetto: "National Courts and the International Law of Human Rights", in Conforti, Benedetto and Francioni, Francesco (eds.): Enforcing International Human Rights in Domestic Courts (Martinus Nijhoff Publishers, The Hague) 3-14, 1997 at 7.
} 
vez que el núcleo central del Derecho Internacional de los Derechos Humanos da sustancia y significado al contenido de estos principios básicos, porque los derechos humanos expresan las opiniones compartidas por todas las naciones sobre los elementos relevantes de justicia y dignidad humana. La Corte concluyó que "una ley nacional impidiendo la huida de un fugitivo desarmado a costa de su vida en contradicción con la Convención, es nula y no puede ser invocada por los acusados" 68 .

10. La Corte Interamericana de Derechos Humanos (en adelante la Corte IDH) desde su primer momento ha señalado que los Estados partes en la Convención Americana sobre Derechos Humanos (en adelante, la CADH) están obligados "a suministrar recursos judiciales efectivos a las víctimas de violación de los derechos humanos (art. 25), recursos que deben ser sustanciados de conformidad con las reglas del debido proceso legal (art. 8.1), todo ello dentro de la obligación general a cargo de los mismos Estados, de garantizar el libre y pleno ejercicio de los derechos reconocidos por la Convención a toda persona que se encuentre bajo su jurisdicción (art. 1 $\left.{ }^{0}\right)^{\text {"69 }}$. Los jueces interamericanos han precisado que estos recursos deben ser adecuados y eficaces. "Que sean adecuados significa que la función de esos recursos, dentro del sistema del derecho interno, sea idónea para proteger la situación jurídica infringida. En todos los ordenamientos internos existen múltiples recursos, pero no todos son aplicables en todas las circunstancias. $\mathrm{Si}$, en un caso específico, el recurso no es adecuado, es obvio que no hay que agotarlo. Así lo indica el principio de que la norma está encaminada a producir un efecto y no puede interpretarse en el sentido de que no produzca ninguno o su resultado sea manifiestamente absurdo o irrazonable"70. "Un recurso debe ser, además, eficaz, es decir, capaz de producir el resultado para el que ha sido concebido"71.

11. Desde la perspectiva de la existencia de los recursos judiciales y el deber del Estado de proveerlos, tal como lo ha reiterado la jurisprudencia de la Corte Interamericana de Derechos Humanos, es pertinente citar la máxima latina " $u b i$

\footnotetext{
${ }^{68}$ Simma, Bruno, Khan, Daniel-Erasmus, Zöckler, Markus and Geiger, Rudolf: "The Role of German Courts in the Enforcement of International Human Rights", in Conforti, Benedetto and Francioni, Francesco (eds.): Enforcing International Human Rights in Domestic Courts (Martinus Nijhoff Publishers, The Hague) 71-109, 1997 at 106.

${ }^{69}$ Corte I.D.H.: Caso Velásquez Rodríguez vs. Honduras. Fondo. Sentencia de 29 de julio de 1988. Serie C No 4, par. 62.

${ }^{70}$ Corte I.D.H.: Caso Velásquez Rodríguez vs. Honduras. Fondo. Sentencia de 29 de julio de 1988. Serie C No 4, par. 63 .

${ }^{71}$ Corte I.D.H.: Caso Velásquez Rodríguez vs. Honduras. Fondo. Sentencia de 29 de julio de 1988. Serie C No 4, par. 66.
} 
jus ibi remedium". Debe siempre haber un foro accesible donde un ofendido pueda presentar su queja y ser amparado en su derecho. No hay derecho (en sentido sustancial del término) sin un recurso que lo ampare.

\section{El ESTÁNDAR DE ACCESO A LA JUSTICIA}

\section{AL QUE SE DEBE AJUSTAR EL ORDEN INTERNO}

1. La Convención Americana sobre Derechos Humanos establece el derecho a recurrir del fallo ante un juez superior en su artículo 8.2.h. Este derecho no se encuentra sometido a ningún tipo de excepciones ${ }^{72}$. El orden jurídico de los Estados debe ajustarse a estas prescripciones ${ }^{73}$. Tanto la Comisión Interamericana de Derechos Humanos (CIDH) como la Corte Interamericana de Derechos Humanos (Corte IDH) han elaborado mayormente la especificidad de estos contenidos.

2. La CIDH ha señalado, en el caso Juan Carlos Abella vs. Argentina, que "[e]s importante destacar que la Convención Americana, a diferencia de la Convención Europea sobre Derechos Humanos y la Declaración Universal de Derechos Humanos, consagra ampliamente el derecho de apelación. La Comisión considera que este recurso, establecido en favor del inculpado, le permite proteger sus derechos mediante una nueva oportunidad para ejercer su defensa. El recurso contra la sentencia definitiva tiene como objeto otorgar la posibilidad a la persona afectada por un fallo desfavorable de impugnar la sentencia y lograr un nuevo examen de la cuestión. Esta revisión en sí tiene como objeto el control del fallo como resultado racional de un juicio justo, conforme a la ley y a los preceptos de garantía, y de la aplicación correcta de la ley penal"74. Además, respondiendo a posibles argumentos de la eficacia de un moderno sistema procesal penal, la Comisión es categórica afirmando que "[n]o obstante las mayores garantías que establece el juicio oral por ser una oportunidad en la que los asuntos son discutidos y confrontados, el derecho del inculpado de delito de recurrir del fallo a una instancia superior es fundamental para garantizar el derecho

\footnotetext{
${ }^{72}$ El Pacto Internacional de Derechos Civiles y Políticos también consagra de manera amplia el mismo derecho en su artículo 14.5: "Toda persona declarada culpable de un delito tendrá derecho a que el fallo condenatorio y la pena que se le haya impuesto, sean sometidos a un tribunal superior, conforme a lo prescrito por la ley".

${ }^{73}$ El Comité de Derechos Humanos de las Naciones Unidas al interpretar el artículo 14(5)-similar al 8(2).h de la Convención Americana de Derechos Humanos- ha afirmado que "no era la intención dejar el derecho de revisión a la discreción de los Estados Partes, ya que los derechos son aquellos reconocidos por el pacto y no meramente aquellos reconocidos por la ley nacional". Comité de Derechos Humanos: Salgar vs. República de Colombia, No 64/179 (1982).

${ }^{74}$ CIDH: Caso Juan Carlos Abella vs. Argentina (caso 11.137) Informe No 55/97, de fecha 18 de noviembre de 1997, par. 259.
} 
de defensa. La oportunidad de recurrir a una segunda instancia en el proceso penal refuerza la protección en contra del error judicial"75.

3. Luego, la Comisión se limita a indicar con precisión los contenidos de este derecho a interponer un recurso ante un tribunal superior. Así, la Comisión señala que "el artículo 8.2.h se refiere a las características mínimas de un recurso que controle la corrección del fallo tanto material como formal. En este sentido, desde un punto de vista formal, el derecho de recurrir el fallo ante un juez o tribunal superior, a que se refiere la Convención Americana, debe en primer lugar proceder contra toda sentencia de primera instancia, con la finalidad de examinar la aplicación indebida, la falta de aplicación o errónea interpretación, de normas de Derecho que determinen la parte resolutiva de la sentencia. La Comisión considera, además, que para garantizar el pleno derecho de defensa, dicho recurso debe incluir una revisión material en relación a la interpretación de las normas procesales que hubieran influido en la decisión de la causa, cuando hayan producido nulidad insanable o provocado indefensión, así como la interpretación de las normas referentes a la valoración de las pruebas, siempre que hayan conducido a una equivocada aplicación o a la no

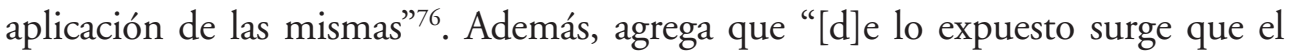
derecho previsto en el artículo 8.2.h requiere la disponibilidad de un recurso que al menos permita la revisión legal, por un tribunal superior, del fallo y de todos los autos procesales importantes. Dicha revisión resulta especialmente relevante respecto a las resoluciones que puedan causar indefensión o daño irreparable por la sentencia definitiva, incluyendo la legalidad de la prueba. El recurso debería constituir igualmente un medio relativamente sencillo para que el tribunal de revisión pueda examinar la validez de la sentencia recurrida en general, e igualmente controlar el respeto a los derechos fundamentales del imputado, en especial los de defensa y el debido proceso" 77 .

4. En el caso Reinaldo Figueredo Planchart vs. la República Bolivariana de Venezuela, la $\mathrm{CIDH}$ afirma el carácter inderogable del derecho a interponer un recurso ante un juez superior y destaca que no se encuentra sujeto a excepciones de ninguna naturaleza. En efecto, la Comisión afirma que "[e]l derecho de recurrir del fallo ante juez o tribunal superior [artículo 8(2) (h) de la convención].

${ }^{75}$ CIDH: Caso Juan Carlos Abella vs. Argentina (caso 11.137) Informe No 55/97, de fecha 18 de noviembre de 1997, par. 260.

${ }^{76}$ CIDH: Caso Juan Carlos Abella vs. Argentina (caso 11.137) Informe No 55/97, de fecha 18 de noviembre de 1997, par. 261.

${ }^{77}$ CIDH: Caso Juan Carlos Abella vs. Argentina (caso 11.137) Informe No 55/97, de fecha 18 de noviembre de 1997, par. 262. 
La Convención Americana establece en su artículo 8(2) (h) que toda persona inculpada de delito tiene derecho, en plena igualdad, a "recurrir del fallo ante juez o tribunal superior". Este derecho constituye un requisito esencial del debido proceso y tiene, además, el carácter de inderogable conforme a lo señalado en el artículo 27(2) de la Convención. A juicio de la Comisión, el derecho de recurrir del fallo implica una revisión de los hechos objeto de la causa, un estudio acabado del juicio, lo cual implica garantías reales a los acusados de que su causa será vista y sus derechos serán garantizados de conformidad con los principios del debido proceso establecidos en el artículo $8^{\circ}$ de la Convención. Este derecho no establece excepciones de ninguna naturaleza. Dicho en otras palabras, "un Estado no puede alegar su derecho interno para evitar cumplir con esta disposición"78.

5. Por su parte, la Corte Interamericana de Derechos Humanos, en el caso Herrera Ulloa ha indicado que "el derecho de recurrir del fallo es una garantía primordial que se debe respetar en el marco del debido proceso legal, en aras de permitir que una sentencia adversa pueda ser revisada por un juez o tribunal distinto y de superior jerarquía orgánica. El derecho de interponer un recurso contra el fallo debe ser garantizado antes de que la sentencia adquiera calidad de cosa juzgada. Se busca proteger el derecho de defensa otorgando durante el proceso la posibilidad de interponer un recurso para evitar que quede firme una decisión que fue adoptada con vicios y que contiene errores que ocasionarán un perjuicio indebido a los intereses de una persona"79. Además, la Corte IDH ha reiterado los principios enunciados en el caso Castillo Petruzzi y agregado que "el proceso penal es uno solo a través de sus diversas etapas, incluyendo la tramitación de los recursos ordinarios que se interpongan contra la sentencia" ${ }^{80}$. Desde el punto de vista de la finalidad del derecho a un recurso ante un tribunal superior, la Corte ha indicado que "[d]e acuerdo al objeto y fin de la Convención Americana, cual es la eficaz protección de los derechos humanos, se debe entender que el recurso

${ }^{78}$ CIDH: Caso Reinaldo Figueredo Planchart vs. la República Bolivariana de Venezuela (caso 11.298) Informe No 50/00, de fecha 13 de abril de 2000, par. 129.

${ }^{79}$ Corte I.D.H.: Caso Herrera Ulloa vs. Costa Rica. Excepciones Preliminares, Fondo, Reparaciones y Costas. Sentencia de 2 de julio de 2004. Serie C No 107, par. 158.

${ }^{80}$ Corte I.D.H.: Caso Herrera Ulloa vs. Costa Rica. Excepciones Preliminares, Fondo, Reparaciones y Costas. Sentencia de 2 de julio de 2004. Serie C No 107, par. 159. Este contenido del derecho de acceso a la justicia se ve complementado con el tema del tiempo en los recursos. "El derecho de acceso a la justicia requiere que se haga efectiva la determinación de los hechos que se investigan y, en su caso, de las correspondientes responsabilidades penales en tiempo razonable, por lo que, en atención a la necesidad de garantizar los derechos de las personas perjudicadas, una demora prolongada puede llegar a constituir, por sí misma, una violación de las garantías judiciales". Corte IDH. Caso Radilla Pacheco vs. México. Excepciones Preliminares, Fondo, Reparaciones y Costas. Sentencia de 23 de noviembre de 2009. Serie C No 209, par. 191. 
que contempla el artículo 8.2.h. de dicho tratado debe ser un recurso ordinario eficaz mediante el cual un juez o tribunal superior procure la corrección de decisiones jurisdiccionales contrarias al derecho. Si bien los Estados tienen un margen de apreciación para regular el ejercicio de ese recurso, no pueden establecer restricciones o requisitos que infrinjan la esencia misma del derecho de recurrir del fallo. Al respecto, la Corte ha establecido que "no basta con la existencia formal de los recursos sino que éstos deben ser eficaces, es decir, deben dar resultados o respuestas al fin para el cual fueron concebidos" ${ }^{\text {. }}$.

6. En el caso Castillo Petruzzi, los jueces interamericanos claramente especificaron que "[e]l derecho de recurrir del fallo, consagrado por la Convención, no se satisface con la mera existencia de un órgano de grado superior al que juzgó y condenó al inculpado, ante el que éste tenga o pueda tener acceso. Para que haya una verdadera revisión de la sentencia, en el sentido requerido por la Convención, es preciso que el tribunal superior reúna las características jurisdiccionales que lo legitiman para conocer del caso concreto. Conviene subrayar que el proceso penal es uno solo a través de sus diversas etapas, tanto la correspondiente a la primera instancia como las relativas a instancias ulteriores. En consecuencia, el concepto del juez natural y el principio del debido proceso legal rigen a lo largo de esas etapas y se proyectan sobre las diversas instancias procesales. Si el juzgador de segunda instancia no satisface los requerimientos del juez natural, no podrá establecerse como legítima y válida la etapa procesal que se desarrolle ante él" $"$.

7. En este último caso, el juez De Roux Rengifo, además, ahondó diciendo que "están reunidos diversos elementos que le permiten a la Corte concluir que no se respetó el derecho de las víctimas a una segunda instancia, pero no porque los organismos encargados de actuar en tal instancia pertenecieran a la justicia militar, sino porque no se desempeñaron como tribunales que reexaminaran la totalidad de los hechos de la causa, ponderaran el valor del acervo probatorio, recaudaran las pruebas adicionales que fueran menester, produjeran, de nuevo, una calificación jurídica de los hechos en cuestión a la luz de las normas penales internas y fundamentaran argumentativamente esa calificación. Sólo por este último orden de razones y aunque no comparta las consideraciones que la condujeron al co-

${ }^{81}$ Corte I.D.H.: Caso Herrera Ulloa vs. Costa Rica. Excepciones Preliminares, Fondo, Reparaciones y Costas. Sentencia de 2 de julio de 2004. Serie C No 107, par. 161.

${ }^{82}$ Corte I.D.H.: Caso Castillo Petruzzi y otros vs. Perú. Fondo, Reparaciones y Costas. Sentencia de 30 de mayo de 1999. Serie C No 52, par. 161; Corte I.D.H.: Caso Lori Berenson Mejía vs. Perú. Fondo, Reparaciones y Costas. Sentencia de 25 de noviembre de 2004. Serie C No 119, par. 192. 
rrespondiente resultado, me uno a la conclusión adoptada por la Corte al declarar que el Estado violó el artículo 8.2.h) de la Convención Americana"83.

8. Desde una perspectiva más general, y refiriéndose al derecho a la tutela judicial efectiva, la Corte IDH ha reiterado en el caso De la Masacre de las Dos Erres, que "según la Convención Americana, los Estados Partes están obligados a suministrar recursos judiciales efectivos a las víctimas de violaciones de los derechos humanos (artículo 25), recursos que deben ser sustanciados de conformidad con las reglas del debido proceso legal (artículo 8.1), todo ello dentro de la obligación general, a cargo de los mismos Estados, de garantizar el libre y pleno ejercicio de los derechos reconocidos por la Convención a toda persona que se encuentre bajo su jurisdicción (artículo 1.1)" 84 .

9. Además, refiriéndose a las garantías de los derechos fundamentales en el orden interno de los Estados, los jueces interamericanos han afirmado que "el recurso de amparo por su naturaleza es 'el procedimiento judicial sencillo y breve que tiene por objeto la tutela de todos los derechos reconocidos por las constituciones y leyes de los Estados Partes y por la Convención'. Asimismo, ha considerado que tal recurso entra en el ámbito del artículo 25 de la Convención Americana, por lo cual tiene que cumplir con varias exigencias, entre las cuales se encuentra la idoneidad y la efectividad" ". En este sentido, en el caso Juan Humberto Sánchez ha especificado que "no basta que los recursos existan formalmente sino que los mismos deben dar resultados o respuestas a las violaciones de derechos humanos, para que éstos puedan ser considerados efectivos". Es decir, que toda persona debe tener acceso a un recurso sencillo y rápido ante jueces o tribunales competentes que amparen sus derechos fundamentales. Dicha garantía "constituye uno de los pilares básicos, no sólo de la Convención Americana, sino del propio Estado de Derecho en una sociedad democrática en el sentido de la Convención" ${ }^{86}$. En efecto, la Corte ha afirmado categóricamente, en el caso Yatama, que "la inexistencia de recursos internos efectivos coloca a las personas en estado de indefensión" ${ }^{87}$.

\footnotetext{
${ }^{83}$ Corte I.D.H.: Caso Castillo Petruzzi y otros vs. Perú. Fondo, Reparaciones y Costas. Sentencia de 30 de mayo de 1999. Serie C No 52. Voto Concurrente del Juez Carlos Vicente de Roux Rengifo.

${ }^{84}$ Corte I.D.H.: Caso De la Masacre de las Dos Erres vs. Guatemala. Excepción Preliminar, Fondo, Reparaciones y Costas. Sentencia de 24 de noviembre de 2009. Serie C No 211, par. 104.

${ }^{85}$ Corte I.D.H.: Caso De la Masacre de las Dos Erres vs. Guatemala. Excepción Preliminar, Fondo, Reparaciones y Costas. Sentencia de 24 de noviembre de 2009. Serie C No 211, par. 107.

${ }^{86}$ Corte I.D.H.: Caso Juan Humberto Sánchez vs. Honduras. Excepción Preliminar, Fondo, Reparaciones y Costas. Sentencia de 7 de junio de 2003. Serie C No 99, par. 121.

87 "La salvaguarda de la persona frente al ejercicio arbitrario del poder público es el objetivo primordial de la protección internacional de los derechos humanos". Corte I.D.H.: Caso Yatama vs. Nicaragua. Excepciones Preliminares, Fondo, Reparaciones y Costas. Sentencia de 23 de junio de 2005. Serie C No 127, par. 167.
} 
10. Finalmente, en concordancia con el carácter inderogable del derecho de acceso a la justicia, reiterado en diversos instrumentos internacionales de derechos humanos pero también de derecho internacional humanitario, los jueces interamericanos han afirmado que el acceso a la justicia pertenece al dominio del ius cogens, con la fuerza imperativa que esto significa para todos los órganos del Estado, particularmente, para el poder legislativo. En el caso Goiburú, los jueces interamericanos expresaron que "[e]l acceso a la justicia constituye una norma imperativa de Derecho Internacional y, como tal, genera obligaciones erga omnes para los Estados de adoptar las medidas que sean necesarias para no dejar en la impunidad esas violaciones, ya sea ejerciendo su jurisdicción para aplicar su derecho interno y el derecho internacional para juzgar y, en su caso, sancionar a los responsables, o colaborando con otros Estados que lo hagan o procuren hacerlo" 88 .

\section{VALORACiÓN FinAL}

1. El Tribunal Constitucional de Chile rechaza efectuar un reproche de constitucionalidad al sistema procesal penal, a pesar de los múltiples defectos que presenta. Tarde o temprano estos defectos exigirán una reforma legislativa que adecue el proceso penal a los estándares y principios mínimos de justicia penal exigidos por el Derecho Internacional de los Derechos Humanos y esperamos que ello ocurra antes que la Corte Interamericana de Derechos Humanos determine la responsabilidad internacional del Estado de Chile por no ajustarse a los estándares de derechos humanos en materia de acceso a la justicia penal.

2. La impresión que causan los casos planteados ante el Tribunal Constitucional es que el proceso penal no satisfaría los estándares de, al menos, el derecho a un recurso pleno y ordinario ante un juez superior. Como ha sostenido la Comisión Interamericana de Derechos Humanos, la oralidad no es suficiente garantía para no respetar el principio de la doble instancia.

3. Estos casos representan un problema mayor que se encuentra presente dentro del ordenamiento jurídico interno y que dice relación con la escasa importancia asignada al derecho de acceso a la justicia y a los defectos en su regulación. Con anterioridad, en otro lugar, nosotros hemos sostenido que el recurso de protección en Chile no satisface el estándar mínimo requerido por la Convención Americana sobre Derechos Humanos, ya que deja sin acción/recurso, esto es, sin tutela

\footnotetext{
${ }^{88}$ Corte I.D.H.: Caso Goiburú y otros vs. Paraguay. Fondo, Reparaciones y Costas. Sentencia de 22 de septiembre de 2006. Serie C No 153, par. 131; Vid. Corte I.D.H.: Caso De la Masacre de las Dos Erres vs. Guatemala. Excepción Preliminar, Fondo, Reparaciones y Costas. Sentencia de 24 de noviembre de 2009. Serie C No 211, par. 140.
} 
judicial efectiva, derechos fundamentales reconocidos en la propia Constitución, transformándolos en último término en derechos de papel.

4. Finalmente, el Tribunal Constitucional tiene interés en observar en sus actuaciones las orientaciones y definiciones proporcionadas por la Corte IDH, especialmente, las precisas consideraciones relativas al acceso a la justicia como una norma de ius cogens, con el objeto de evitar poner al Estado de Chile en situación de responsabilidad internacional. 
